\title{
LA ESTRUCTURA DE CAPITAL DE LAS PEQUEÑAS Y MEDIANAS EMPRESAS ARGENTINAS*
}

\begin{abstract}
Anahí Briozzo ${ }^{* *}$
Hernán Vigier ${ }^{* * *}$
\end{abstract}

\section{Resumen}

En esta investigación se propone que en el financiamiento de las pequeñas y medianas empresas (PyMEs) influyen ciertos factores propios de la demanda, derivados de una característica fundamental de este tipo de firmas: el entrelazamiento empresa- propietario. Los mismos se suman a las variables tradicionalmente estudiadas, que son producto de las asimetrías de información entre firmas y proveedores de fondos. Sobre la base de un estudio de campo realizado en la ciudad de Bahía Blanca en el periodo julio-octubre de 2006, se encuentra evidencia que apoya la relevancia de las variables propuestas. Esto constituye un avance hacia el desarrollo de modelos que caractericen la naturaleza distintiva de las pequeñas firmas.

Clasificación JEL: G32

Palabras clave: pequeñas empresas - decisiones de financiamiento - estructura de capital

* Este trabajo es una adaptación de parte de la Tesis de Doctorado en Economía "Identificación de los Determinantes de la Estructura de Capital de las Pequeñas y Medianas Empresas Argentinas", presentada por la autora en el Departamento de Graduados de la Universidad Nacional del Sur, Bahía Blanca, 2007 y dirigida por el Dr. Hernán Vigier. La investigación fue realizada con una Beca Interna Doctoral del CONICET.

** Departamento de Ciencias de la Administración, Universidad Nacional del Sur. CONICET, e.mail: abriozzo@uns.edu.ar

*** Departamento de Economía, Universidad Nacional del Sur. Universidad Provincial del Sudoeste, e.mail: hvigier@uns.edu.ar 


\begin{abstract}
In this research we propose that the financial structure of small and medium enterprises (SME) is influenced by demand side factors, which are based on a fundamental characteristic of these firms: the owner-firm intertwinement. This approach is complementary to the traditional view for small firms that focus on information asymmetries between firms and external fund providers. Studying a group of firms from Bahía Blanca, we find evidence supporting the new approach. We consider these results as a contribution to the understanding and modelling of SME's distinctive characteristics.
\end{abstract}

JEL Classification: G32

Keywords: small firms - financing decisions - capital structure

\title{
INTRODUCCION
}

Estudiar a las pequeñas y medianas empresas (PyMEs) como objeto de investigación responde a distintos motivos; siguiendo a Storey (1994) éstos pueden agruparse en el diseño de políticas por un lado y el avance en el conocimiento microeconómico en sí mismo por el otro.

En el campo del diseño de políticas, si bien los pequeños empresarios enfatizan la necesidad de una solución inmediata a los problemas de hoy, los programas diseñados para apoyar a las PyMEs (en cuanto a innovación, creación de empleo, financiamiento) deben responder a políticas de largo plazo. Además, las decisiones de regulación deben tomarse cuidadosa e informadamente, ya que no siempre coinciden los intereses de los propietarios de las pequeñas empresas con los intereses de la sociedad. 
Por otra parte, es necesario reconocer que las pequeñas empresas se distinguen de las grandes firmas en factores que van más allá del tamaño, y por lo tanto no se puede aplicar directamente un modelo desarrollado para grandes firmas a las PyMEs. En primer lugar, la unificación entre dirección y propiedad genera un "entrelazamiento" entre la empresa y su propietario, que plantea subjetividades en la toma de decisiones que están ausentes en la firma grande con capital abierto, expuesta a la evaluación del mercado de capitales. Como son estructuras societarias de capital cerrado, el administrador - propietario no puede diversificar su cartera, o le resulta muy difícil, lo cual afecta su posición frente al riesgo. Además, la falta de profesionalización lleva a problemas en la gestión, como la escasa especialización en las funciones organizacionales y la miopía en la planificación.

Toda empresa nueva o en marcha requiere financiamiento, tanto para su creación como para su desarrollo a través del tiempo. En general existen dos fuentes básicas de financiación: la deuda y el capital propio. Los pasivos o deuda pueden ser dos tipos: operativos, es decir, son generados durante el ciclo de operaciones de la empresa, y financieros, los cuales devengan intereses explícitos. En función del tratamiento dado a los pasivos operativos, puede hablarse de estructura de capital, concepto que engloba únicamente derechos financieros y capital propio, o de estructura de financiamiento, que incluye además de estos conceptos, a los pasivos operativos.

La literatura sobre la estructura de capital se ha desarrollado a partir de la segunda mitad del siglo XX, principalmente en un marco de grandes empresas y mercados de capitales desarrollados. En la línea de las pequeñas empresas, autores como Hamilton y Fox (1998) y Hutchinson, Hall y Michaelas (1998) proponen una jerarquía financiera de 
preferencia por el autofinanciamiento antes que el endeudamiento, basada en el deseo de los propietarios de mantener el control de la empresa. Mientras la visión original de la jerarquía financiera se basa en el efecto señalizador de la emisión de acciones en un contexto de información asimétrica, la propuesta relativa a las PyMEs puede considerarse como una explicación del lado de la demanda.

Con respecto a los estudios empíricos a nivel internacional, éstos muestran que las pequeñas empresas emplean endeudamiento financiero, y en particular a largo plazo, en proporciones menores que las grandes empresas.

A fines de explicar esta diferencia, el estudio del financiamiento de las pequeñas empresas fundamentalmente se ha centrado en el racionamiento de la oferta de crédito debido a las asimetrías de información entre las empresas y el sistema financiero (principalmente bancos). De hecho, las políticas de apoyo financiero a pequeñas empresas están construidas sobre esta línea teórica de fallas de mercado. En la Argentina, la Subsecretaría de la Pequeña y Mediana Empresa y Desarrollo Regional (SEPyME) ha desarrollado programas con el objetivo de reducir los costos de financiamiento mediante la bonificación de tasas de interés, y de requerimientos de garantías a las empresas con el sistema de sociedades de garantía recíprocas.

En esta investigación se retoman los aportes de Hamilton y Fox (1998) y Hutchinson et al (1998), y se propone un enfoque del financiamiento de las pequeñas empresas basado en las características de la demanda, como visión complementaria a los desarrollos ya existentes. Bajo esta premisa se propone una explicación complementaria a los enfoques tradicionales, incorporando factores como la edad del propietario, su actitud 
frente al endeudamiento personal, sus objetivos con respecto a la empresa, los costos emocionales asignados a una potencial quiebra, la profesionalización del management y la naturaleza familiar del negocio. De esta forma se incluye la dimensión personal y conductual a la decisión de financiamiento. Estas variables se agrupan bajo tres enfoques: la visión gerencial, el ciclo de vida del administrador- propietario y el ciclo de vida de la empresa familiar.

La pregunta de investigación que se desarrolla en este trabajo consiste en identificar los determinantes del empleo de pasivos financieros. Las estimaciones econométricas se realizan a través de un modelo probit. A fines de contrastar empíricamente las hipótesis de investigación se realizó un estudio de campo en 140 empresas de la ciudad de Bahía Blanca, durante el periodo julio-octubre 2006. Se incluyen en este relevamiento puntos sobre los cuales no existe información previa, como una estimación de los costos personales de quiebra, los objetivos del administrador propietario con respecto a la empresa y su experiencia personal con el endeudamiento.

Los resultados obtenidos coinciden con los esperados para las variables edad del empresario, empleo de crédito personal y asimetrías de información. No se encuentra evidencia para el ciclo de vida de la empresa familiar.

La estructura de este trabajo es la siguiente: primero se presenta el marco teórico y los antecedentes empíricos, luego se describe la metodología. Los resultados de las estimaciones constituyen la sección siguiente, finalizando el trabajo con las conclusiones. 


\section{MARCO TEORICO Y ANTECEDENTES}

\section{1. Desarrollos teóricos}

El análisis de la estructura de capital se construye a partir de las proposiciones de Modigliani y Miller $(1958,1963)$ sobre la irrelevancia del financiamiento en un mercado de capitales perfecto. Luego se incorporan imperfecciones como impuestos corporativos y personales, costos de quiebra y problemas de agencia, llegando así al enfoque de trade off estático. El mismo propone la existencia de una estructura óptima que maximiza el valor de la empresa, en función de balancear los beneficios y costos del endeudamiento. Los argumentos tradicionales del trade off se resumen en el Cuadro 1 (paneles A, B y C).

\section{Cuadro 1.A - Argumentos del trade-off: Impuestos}

\begin{tabular}{|c|l|c|}
\hline \multicolumn{2}{|c|}{ Argumento } & Autores \\
\hline $\begin{array}{c}\text { Impues- } \\
\text { tos } \\
\text { corporati } \\
\text { vos }\end{array}$ & $\begin{array}{l}\text { El escudo fiscal es la principal ventaja de } \\
\text { la deuda. Depende del sistema impositivo, } \\
\text { la forma legal de la empresa y la } \\
\text { probabilidad de generar beneficios futuros. }\end{array}$ & $\begin{array}{c}\text { Modigliani y } \\
\text { Miller (1963) }\end{array}$ \\
\hline $\begin{array}{c}\text { Impues- } \\
\text { tos } \\
\text { persona- } \\
\text { les }\end{array}$ & $\begin{array}{l}\text { Los impuestos sobre la renta de dividendos } \\
\text { e intereses reducen el valor del escudo } \\
\text { fiscal, ya que los inversores requieren una } \\
\text { mayor tasa antes de impuestos. }\end{array}$ & Miller (1977) \\
\hline $\begin{array}{c}\text { Escudos } \\
\text { no deuda }\end{array}$ & $\begin{array}{l}\text { Los rubros que son deducibles de } \\
\text { impuestos, como las amortizaciones y } \\
\text { gastos de I\&D, pueden actúan como } \\
\text { sustitutos del rol fiscal de la deuda. }\end{array}$ & $\begin{array}{c}\text { MeAngelo y } \\
\text { Masulis (1980) }\end{array}$ \\
\hline
\end{tabular}


Cuadro 1.B - Argumentos del trade-off: costos de quiebra

\begin{tabular}{|c|c|c|}
\hline & Argumento & Autores \\
\hline $\begin{array}{l}\text { Costos } \\
\text { directos }\end{array}$ & $\begin{array}{l}\text { Son los costos legales y administrativos } \\
\text { de la reorganización o liquidación de la } \\
\text { empresa. Su valor esperado aumenta con } \\
\text { la probabilidad de quiebra. }\end{array}$ & $\begin{array}{c}\text { Kraus y } \\
\text { Litzemberger } \\
\text { (1973), Kim } \\
\text { (1978), Brennan }\end{array}$ \\
\hline $\begin{array}{c}\text { Costos } \\
\text { indirectos }\end{array}$ & $\begin{array}{l}\text { Son costos de oportunidad que afectan el } \\
\text { flujo de fondos operativo de la empresa, } \\
\text { como pérdida de ventas o reducción de } \\
\text { plazo de crédito de los proveedores. }\end{array}$ & $\begin{array}{c}\text { (1978), entre } \\
\text { otros }\end{array}$ \\
\hline
\end{tabular}

Fischer, Heinkel, y Zechner (1989) y Leland (1994) presentan modelos dinámicos de trade off que incluyen los costos de ajuste de la estructura de financiamiento. Bajo la existencia de costos de ajuste, las empresas ajustarán su estructura hacia su ratio objetivo sólo si los beneficios generados por este ajuste (el mayor valor de la empresa) superan a los costos de cambio. Estas fricciones provocarían una persistencia de la estructura de capital, aún si las empresas persiguen una estructura óptima.

El efecto de la señalización en la estructura de capital proviene de dos fuentes: primero el efecto señalizador de la deuda (Ross, 1977), que establece que los insiders pueden emplear la estructura de capital para señalizar a los inversores externos sobre la calidad de la empresa. Por otra parte, la jerarquía financiera o pecking order (Myers 1984, Myers y Majluf 1984) se basa en el 
efecto señalizador de la emisión de acciones, y concluye la existencia de un orden de preferencias que llevan a que las empresas agoten el autofinanciamiento antes de emitir deuda. La jerarquía financiera puede replantearse para las pequeñas empresas considerando los efectos de los costos de transacción y el deseo de mantener la flexibilidad. Relacionado con este enfoque, el ciclo financiero de crecimiento (Berger y Udell 1998) la firma señala que las asimetrías de información evolucionan a lo largo de la vida de la empresa. Desde esta visión, no existe una estructura óptima.

\section{Cuadro 1.C - Argumentos del trade-off: problemas de agencia}

\begin{tabular}{|c|c|c|}
\hline \multicolumn{2}{|r|}{ Argumento } & Autores \\
\hline $\begin{array}{l}\text { Costos de } \\
\text { agencia } \\
\text { de la } \\
\text { deuda }\end{array}$ & $\begin{array}{l}\text { Las asimetrías entre insiders y acreedores } \\
\text { causan el problema de sustitución de } \\
\text { activos. Los acreedores requieren } \\
\text { mayores tasas para cubrir los costos de } \\
\text { monitoreo. }\end{array}$ & \multirow{2}{*}{$\begin{array}{l}\text { Fama y Miller } \\
\text { (1972), Jensen y } \\
\text { Meckling } \\
\text { (1976), } \\
\text { Diamond (1989) }\end{array}$} \\
\hline $\begin{array}{l}\text { Costos de } \\
\text { agencia } \\
\text { de las } \\
\text { acciones }\end{array}$ & $\begin{array}{l}\text { Son causa de asimetrías entre múltiples } \\
\text { propietarios, o entre propietarios y } \\
\text { managers cuando hay separación de } \\
\text { propiedad y control. }\end{array}$ & \\
\hline $\begin{array}{l}\text { Costos de } \\
\text { agencia } \\
\text { del flujo } \\
\text { de fondos }\end{array}$ & $\begin{array}{l}\text { La deuda puede tener un rol de control, } \\
\text { ya que reduce el flujo de fondos de la } \\
\text { empresa, obligando a los managers a } \\
\text { administrar el negocio eficientemente. }\end{array}$ & Jensen (1986) \\
\hline
\end{tabular}

Fuente: Elaboración propia. 
La corriente de interacciones de los mercados de insumos y productos toma características de la teoría de organización industrial, considerando los efectos de las estrategias de la empresa sobre su estructura de capital, y viceversa. Estos efectos pueden resultar de estrategias en el mercado de insumos (relación con sus proveedores) o de productos (clientes y competidores) de la empresa. Los principales argumentos bajo este enfoque se resumen en el Cuadro 2 (paneles A y B).

\section{Cuadro 2.A - Argumentos de la interacción en los mercados de productos}

\begin{tabular}{|l|l|l|}
\hline $\begin{array}{l}\text { Interacciones con el } \\
\text { mercado de productos }\end{array}$ & \multicolumn{1}{|c|}{ Argumento } & \multicolumn{1}{c|}{ Implicaciones } \\
\hline $\begin{array}{l}\text { Importancia de la } \\
\text { reputación } \\
\text { Maksimovic and } \\
\text { Titman (1991) }\end{array}$ & $\begin{array}{l}\text { La deuda puede } \\
\text { reducir la capacidad } \\
\text { de la firma de ofrecer } \\
\text { creíblemente } \\
\text { productos de alta } \\
\text { calidad. }\end{array}$ & $\begin{array}{l}\text { Se la reputación importa, } \\
\text { se espera que la empresa } \\
\text { tenga menos deuda. }\end{array}$ \\
\hline $\begin{array}{l}\text { Competencia } \\
\text { estratégica } \\
\text { Brander y Lewis } \\
\text { (1986) }\end{array}$ & $\begin{array}{l}\text { A través de la deuda } \\
\text { las firmas pueden } \\
\text { comprometerse } \\
\text { creíblemente a seguir } \\
\text { estrategias de } \\
\text { producción más } \\
\text { agresivas. }\end{array}$ & $\begin{array}{l}\text { Las empresas en } \\
\text { oligopolios tenderán a } \\
\text { tener más deuda que } \\
\text { monopolistas o firmas en } \\
\text { mercados competitivos. }\end{array}$ \\
\hline $\begin{array}{l}\text { Diferentes estrategias } \\
\text { competitivas afectan } \\
\text { en forma distinta a la } \\
\text { especificidad de los } \\
\text { competitivas } \\
\text { Jordan et al (1998) }\end{array}$ & $\begin{array}{l}\text { activos de la empresa, } \\
\text { afectando el riesgo } \\
\text { operativo de la firma. }\end{array}$ & $\begin{array}{l}\text { Empresas que sigan } \\
\text { diversificación tendrán } \\
\text { acceso restringido a la } \\
\text { deuda, o mayor costo, de } \\
\text { endeudarse. }\end{array}$ \\
\hline \multicolumn{2}{|l}{} \\
\hline
\end{tabular}


Cuadro 2.B - Argumentos de la interacción en los mercados de insumos

\begin{tabular}{|l|l|l|}
\hline $\begin{array}{l}\text { Interacciones con el } \\
\text { mercado de insumos }\end{array}$ & \multicolumn{1}{|c|}{ Argumento } & \multicolumn{1}{|c|}{ Implicaciones } \\
\hline $\begin{array}{l}\text { Teoría de co- } \\
\text { inversión de los } \\
\text { stakeholder } \\
\text { (Titman 1984) } \\
\text { (Titman y Wessels } \\
1988)\end{array}$ & $\begin{array}{l}\text { La quiebra de la } \\
\text { empresa impone } \\
\text { costos a sus clientes, } \\
\text { empleados y } \\
\text { proveedores. }\end{array}$ & $\begin{array}{l}\text { Se espera que las firmas } \\
\text { que producen bienes } \\
\text { únicos o especializados } \\
\text { empleen menos deuda. }\end{array}$ \\
\hline & $\begin{array}{l}\text { Una firma es más } \\
\text { vulnerable a una } \\
\text { quiebra si se suspende } \\
\text { el suministro de } \\
\text { factores de producción } \\
\text { especializados. } \\
\text { Si una firma mantiene } \\
\text { liquidez alta los } \\
\text { trabajadores pueden } \\
\text { verse alentados a pedir } \\
\text { incrementos salariales. }\end{array}$ & $\begin{array}{l}\text { espera que las } \\
\text { empresas empleen más } \\
\text { deuda si sus trabajadores } \\
\text { están poco } \\
\text { especializados y tienen } \\
\text { un sindicato poderoso. }\end{array}$ \\
$\begin{array}{l}\text { producción } \\
\text { especializados y } \\
\text { poder del sindicato de } \\
\text { trabajadores } \\
\text { Sarig (1998) }\end{array}$ & \multicolumn{2}{|l}{} \\
\hline
\end{tabular}

Fuente: Elaboración propia.

Las finanzas conductuales constituyen un nuevo enfoque, que ha surgido desde principios de los noventa, en parte como respuesta a las dificultades que enfrenta el paradigma tradicional para explicar ciertos fenómenos. Siguiendo la definición de Barberis y Thaler (2003), este nuevo enfoque sostiene que algunos fenómenos financieros pueden ser mejor comprendidos mediante modelos en los cuales los agentes no son completamente racionales. Es decir, se relaja alguno de los supuestos que dan base a la racionalidad: en algunos modelos los agentes no actualizan sus creencias correctamente, mientras que en otros toman decisiones que no sería normativamente correctas, en cuanto a que no maximizan su utilidad esperada. 
Existen distintas formas de clasificar los modelos desarrollados dentro de las finanzas corporativas conductuales. En particular, interesa aquí la clasificación de Shefrin (2001) que distingue dos enfoques: del inversor irracional (con managers racionales), y del manager irracional (con inversores racionales). Estos son dos impedimentos conductuales al proceso de maximización del valor de la firma, el primero de naturaleza externa y el segundo, interna.

Baker, Ruback y Wurgler (2004) advierten que estos enfoques tiene implicaciones distintas. Cuando la fuente primaria de irracionalidad proviene de los inversores, la maximización del valor a largo plazo requiere de inmunizar a los managers de presiones de corto plazo en los precios de las acciones, para que puedan tomar decisiones que resulten poco populares entre los inversores. Cuando la fuente de irracionalidad son los managers, para lograr la eficiencia se necesita reducir la discreción y obligar a los managers a responder a las señales en los precios de mercado.

Bajo el enfoque del inversor irracional, el manager racional balancea tres objetivos contrapuestos: maximizar el valor fundamental de la empresa, maximizar el valor de las acciones, y explotar los errores en la valuación de las acciones (market timing). El problema radica en que bajo mercados ineficientes, el primer y segundo objetivo no necesariamente coinciden: para satisfacer demandas corto-placistas de los inversores, puede interesar emprender ciertos proyectos, o no invertir. Las implicaciones son que la irracionalidad de los inversores puede llevar a políticas de inversión sub-óptimas, y a una política de financiamiento de market timing (emitir acciones cuando están sobrevaluadas y re-comprarlas cuando están subvaluadas). 
Por otra parte, en el enfoque de managers irracionales éstos conviven con inversores racionales. Para que la irracionalidad del manager tenga efecto, el gobierno corporativo debe ser limitado en cuanto a su capacidad de restringir la discrecionalidad del manager. Baker, Ruback y Wurgler (2004) señalan que la mayor parte de estos modelos se basan en el optimismo y la sobreconfianza, lo cual puede ser representando como una sobrestimación de la media (optimismo) y una subestimación de la volatilidad (sobreconfianza). Además, la sobreconfianza lleva a tomar más riesgos. En este caso los managers balancean dos objetivos: maximizar el valor fundamental percibido, y minimizar el costo de capital percibido, y actúan en beneficio de los accionistas actuales. Como el costo de capital percibido es inferior al real, los managers sobreinvierten. Para la política de financiamiento, la implicancia es una jerarquía financiera, ya que un manager optimista evita emitir acciones (porque cree que están subvaluadas).

Por último, Stiglitz y Weiss (1981) analizan cómo las asimetrías de información afectan a la oferta de fondos de los bancos, demostrando que el mercado de préstamos se caracteriza por el racionamiento del crédito. $\mathrm{Al}$ dar un préstamo, los bancos se preocupan por la tasa de interés que reciben, y por el riesgo del préstamo. Sin embargo, en un contexto de información asimétrica, la tasa de interés que el banco cobra afecta el riesgo de los créditos, de dos formas posibles: a) clasificando a los prestamistas potenciales - el efecto de selección adversa, o b) afectando las acciones de los prestamistas - el efecto de incentivos.

Petersen y Rajan (1994) observan que bajo este contexto, los cambios en el ratio de deuda de una empresa pueden deberse a cambios en la demanda o en la oferta de crédito. 
Si las instituciones limitan el acceso al crédito, una vez que hayan agotado las fuentes más baratas (el financiamiento interno ${ }^{1}$, mediante los flujos de fondos generados) las empresas recurrirán a fondos más costosos, siempre que el rendimiento de sus inversiones supere el costo de esos fondos. El crédito comercial se constituye entonces en un sustituto, más costoso, de los pasivos financieros.

De estos enfoques teóricos surgen una serie de factores relevantes que influyen en las decisiones de financiamiento, que pueden agruparse en características generales de la economía y particulares de las empresas, como se muestra en el Cuadro 3 (paneles A y B).

Cuadro 3. A-Variables relevantes y su efecto esperado:

Características de la economía general

\begin{tabular}{|l|c|c|c|}
\hline \multirow{2}{*}{ Determinante } & \multicolumn{3}{|c|}{ DT/AT } \\
\cline { 2 - 4 } & TO & PO & P I \\
\hline Tasa de impuestos corp. & $+/ 0$ & & \\
\hline Tasa imp. personales & - & & \\
\hline Escudos no deuda & - & & \\
\hline
\end{tabular}

Notas: TO: Trade off, PO: Pecking order, PI: interacciones producto-insumo, DT: Deuda total, AT: Activo total,

${ }^{1}$ En la teoría de la jerarquía financiera vuelve a aparecer el financiamiento interno como la primera fuente preferida de fondos. 


\section{Cuadro 3.B - Variables relevantes y su efecto esperado: Características de la empresa}

\begin{tabular}{|l|c|c|c|}
\hline \multirow{2}{*}{ Determinante } & \multicolumn{3}{|c|}{ DT/AT } \\
\cline { 2 - 4 } & TO & PO & P I \\
\hline Tamaño & + & + & \\
\hline Antigüedad & + & $?$ & \\
\hline Rentabilidad & + & - & \\
\hline Crecimiento & - & + & \\
\hline Dividendos & & + & \\
\hline Tangibilidad & + & & \\
\hline Singularidad & - & & - \\
\hline Activos no corrientes /Activos totales & & & + \\
\hline Especialización de los trabajadores & & & - \\
\hline Fuerza del sindicato & & & + \\
\hline Variabilidad de los ingresos & - & & \\
\hline Variabilidad de la demanda & & & + \\
\hline Apalancamiento operativo & - & & \\
\hline Riesgo de quiebra & - & & \\
\hline Tipo de competencia & & & $\mathrm{a}$ \\
\hline Estrategia de innovación & & & $\mathrm{b}$ \\
\hline Relevancia de la reputación & & & - \\
\hline Concentración de la propiedad & $?$ & - & \\
\hline Forma legal & $\mathrm{c}$ & - & \\
\hline Relación con los acreedores & + & + & \\
\hline
\end{tabular}

Fuente: Elaboración propia.

Notas:

? Resultados no significativos o contradictorios

a - Los oligopolistas tenderán a tener más deuda que los monopolistas y empresas en mercados competitivos.

b - Las empresas que buscan la innovación tendrán menos deuda.

c - Por el lado del efecto oferta, se puede esperar que los bancos estén dispuestos a dar mayor crédito a estructuras sin limitación de la responsabilidad, ya que el empresario tendrá un mayor incentivo a repagar el préstamo. En cambio, considerando el efecto demanda, puede esperarse que empresarios en estructuras sin limitación de la responsabilidad sean más cautelosos para tomar créditos, dado el fuerte impacto que el incumplimiento tendría en su vida personal. 


\section{2. Antecedentes empíricos}

En distintos países se han realizado estudios empíricos buscando comprender los factores que influyen en el financiamiento de las PyMEs. Aun cuando hay que reconocer las potenciales diferencias estructurales de los distintos países entre sí y con respecto a Argentina, en esta sección se analizan distintos ensayos sobre la problemática estudiada, con el objeto de obtener un panorama general.

Existen determinadas diferencias institucionales entre países que podrían afectar las decisiones de financiamiento de las empresas. Por ejemplo, Fan, Titman y Twite (2006) consideran la posibilidad de hacer cumplir los contratos legales, el sistema tributario, y las características de los proveedores de capital. Hall et al (2006) agregan el efecto de la cultura nacional y las diferencias en las estructuras de gobierno corporativo.

A pesar de estas diferencias, Fan, Titman y Twite (2006), entre otros ${ }^{2}$, encuentran para las grandes empresas que los determinantes del apalancamiento son aproximadamente consistentes entre países. Para pequeñas empresas, Hall et al (2006) encuentran coincidencia general en el signo de los determinantes del endeudamiento entre empresas del ex - bloque soviético y empresas europeas de otra localización ${ }^{3}$.

${ }^{2}$ Rajan y Zingales (1995), por ejemplo.

${ }^{3}$ Excepto para tamaño y deuda a corto plazo, y antigüedad de la empresa y deuda a largo plazo. 
Cuadro 4 - Autores de trabajos empíricos y su localización

\begin{tabular}{|l|l|}
\hline País & Trabajos \\
\hline España & $\begin{array}{l}\text { Cardone Riportella y Carzola -Papis (2001) (RP), Cardone } \\
\text { Riportella y Casasola Martínez (2003) (RM), Aybar-Arias, C., } \\
\text { Casino-Martínez, A., y López-Gracia, J.(2003) (AM), Sorgob } \\
\text { Mira (2005) (SM) }\end{array}$ \\
\hline Portugal & Serrasqueiro y Raposo (2003) (SR) \\
\hline $\begin{array}{l}\text { Francia } \\
\text { y Grecia }\end{array}$ & Daskalakis, N y Psillaki, M (2005) (DP) \\
\hline Polonia & Klapper, L, Sarria-Allende,V., y Zaidi,R (2006) (KZ) \\
\hline $\begin{array}{l}\text { Reino } \\
\text { Unido }\end{array}$ & $\begin{array}{l}\text { Chittenden et al (1996) (CH), Jordan et al (1998) (JO), Hutchison } \\
\text { (2003) (HU) }\end{array}$ \\
\hline Irlanda & Mac an Bhaird, C y Lucey, B.(2006 ) (BL) \\
\hline $\begin{array}{l}\text { ex } \\
\text { Alem.Oc }\end{array}$ & Van der Wifst y Thurik(1993) (WT) \\
\hline $\begin{array}{l}\text { Europa } \\
\text { del Este }\end{array}$ & Klapper, L; Sulla, V., y Sarria-Allende, V (2002) (KS) \\
\hline EEUU & Petersen y Rajan (1994) (PR), Gibson(2002) (GI) \\
\hline Canadá & Gellatly, G., Riding, A., y Thornhill, S. (2003) (GT) \\
\hline Australia & $\begin{array}{l}\text { Romano, C., Tanewski, G. y Smyrnios, K (2000) (empresas } \\
\text { familiares) (RO) }\end{array}$ \\
\hline $\begin{array}{l}\text { Nueva } \\
\text { Zelanda }\end{array}$ & Hamilton y Fox (1998) (HF) \\
\hline
\end{tabular}

Fuente: Elaboración propia.

Teniendo en cuenta estas consideraciones, en la revisión empírica de esta sección se describe el signo del efecto y no su medida cuantitativa.. En el Cuadro 4 se indican los autores y países de origen de los 18 estudios reseñados. Siguiendo a Harris y Raviv (1991), se presentan los resultados empíricos sin analizar los métodos empleados en estos estudios, sólo se los enumera. El 
objetivo es lograr un conocimiento suficientemente representativo de los avances en esta área de investigación.

Los resultados individuales de los trabajos citados se exponen en el Cuadro 5. La evidencia más fuerte apunta a una asociación negativa de la rentabilidad, antigüedad de la empresas, impuestos corporativos y escudos no deuda, con el apalancamiento, mientras que el tamaño de a empresa y el crecimiento presentan efectos positivos. El resultado de las variables rentabilidad y crecimiento parece alinearse con las predicciones de la jerarquía financiera, pero se deber ser cuidadoso en la interpretación, ya que la formulación dinámica del trade off también podría explicar este resultado.

Para la Argentina, existen estudios descriptivos llevados a cabo por el Observatorio PyME desde hace más de una década, y más recientemente, el proyecto Mapa PyME de la Sub-Secretaría de la Pequeña y Mediana Empresa y Desarrollo Regional. Para la ciudad de Bahía Blanca, los antecedentes se encuentran en Salloum y Vigier $(1997,1999)$ y Salloum, Foco y Vigier (2001). En cuanto a trabajos sobre determinantes de las decisiones de financiamiento, Filippo, Kostzer y Schleser (2004), desarrollan un modelo de racionamiento crediticio a PyMEs en la Argentina, y encuentran que el tamaño, medido como número de empleados en términos formales, incide positivamente en la probabilidad de acceso al crédito bancario. Bebczuk (2004) encuentra que el tamaño de la empresa (medido como ventas) no influye en la probabilidad de obtener un crédito bancario. En cambio, el empleo de giro en descubierto aumenta la probabilidad de obtener un crédito bancario. 


\section{METODOLOGIA}

II. 1. Preguntas e hipótesis de investigación

En esta investigación se estudian las variables que inciden en la estructura observada (empleo de pasivos financieros en un momento dado), donde actúan factores de la demanda y la oferta. La pregunta de investigación es: ¿qué factores diferencian a las empresas que emplean pasivos financieros (excluido giro en descubierto) de las que no?

Los motivos para centrarse en el empleo de pasivos financieros en vez de la deuda total ${ }^{4}$, radican por un lado en que son dos decisiones diferentes (que un extremo teórico serían independientes entre sí), por lo cual no puede esperarse que estén influenciados exactamente por los mismos determinantes, o en la misma forma. Por otra parte, la caracterización del fenómeno como presencia - ausencia responde a las características del financiamiento de las pequeñas empresas argentinas, que según los datos reportados por el Observatorio PyME (2004, 2005, 2006) emplean en baja proporción pasivos financieros.

Las hipótesis de investigación constituyen las respuestas tentativas a esta pregunta, planteadas en términos de los factores explicativos propuestos bajo lo que en este trabajo se denomina la visión gerencial, y los enfoques de ciclo de vida del empresario y de la empresa familiar.

La visión gerencial considera cómo influyen las características personales de los propietarios-administradores, y la forma en que administran su empresa, en las decisiones de financiamiento. En particular, los factores considerados son:

\footnotetext{
${ }^{4}$ Se considera el rol de los pasivos operativos como sustituto.
} 


\section{Cuadro 5 - Determinantes empíricos según referencias en el Cuadro 4}

\begin{tabular}{|c|c|c|c|c|c|c|c|c|c|c|c|c|c|c|c|c|c|c|c|}
\hline DT/AT & \multicolumn{4}{|c|}{ Esparia } & SR & $\mathrm{DP}$ & $\mathrm{KZ}$ & \multicolumn{3}{|c|}{ UK } & $\mathrm{BL}$ & WT & $\mathrm{KS}$ & \multicolumn{2}{|c|}{ EEUUU } & $\mathrm{GT}$ & $\mathrm{RO}$ & $\mathrm{HF}$ & $\begin{array}{c}\text { Resultado } \\
\text { general }\end{array}$ \\
\hline Tamaro & ns & + & + & + & & + & + & - & ns & & ns & ns & + & + & + & & + & & + \\
\hline Crecimienth & & + & + & + & & + & + & ns & ns & ns & & & + & & & + & & & + \\
\hline Estructura de los activos & & - & & + & & - & + & - & + & & & ns & - & & + & & & & $?$ \\
\hline Sinzularidad & & & & & & & & & ns & & & & & & & - & ns & & $?$ \\
\hline $\begin{array}{l}\text { Separación propiedad- } \\
\text { control }\end{array}$ & ns & & & & & & & & & & + & & & & & & & & $?$ \\
\hline $\begin{array}{l}\text { Concentración de la } \\
\text { estructura de propiedad }\end{array}$ & & & & & & & - & & & & & & & & & & & & - \\
\hline $\begin{array}{l}\text { Concertración de la } \\
\text { industria }\end{array}$ & & & & & & & + & & & & & & & & & & & & + \\
\hline Planificación formal & & & & & & & & & & & & & & & & & + & & + \\
\hline Antiguedad como CEO & ns & & & & & & & & & & & & & & & & & & $?$ \\
\hline Edad del propietario & & & & & & & & & & & & & & & & & ns & & $?$ \\
\hline Objetivo de crear valor & & & & & & & & & & & & & & & & & + & & + \\
\hline Control Farriliar & & & & & & & & & & & & & & & & & - & & - \\
\hline
\end{tabular}

Fuente: Elaboración propia. 
- Los objetivos del empresario con respecto al negocio, que pueden variar desde los objetivos financieros tradicionales, como incrementar el valor de la empresa, o el crecimiento de las ventas, a objetivos más personales como dar trabajo a los miembros de la familia, pasar la empresa a la siguiente generación o mantener un estilo de vida. Carland, Carland, Carland y Pearce (1995), sugieren que habría diferencias en la propensión al riesgo entre fundadores que se enfocan principalmente en el crecimiento y la rentabilidad, propietarios orientados a fines más personales o familiares, y los gerentes sin participación en la propiedad.

- La actitud respecto al financiamiento con deuda y las experiencias anteriores con el endeudamiento a nivel personal. Se espera que tenga una asociación positiva con el empleo de pasivos financieros, ya que estaría indicando una mayor disposición a asumir riesgos financieros. Esta actitud positiva puede deberse a tener experiencia previa con el endeudamiento a nivel personal, implicando una familiarización con el apalancamiento, mientras que para quienes no tengan esta experiencia, actuaría la aversión por la incertidumbre. A su vez, esta experiencia previa puede verse como una disminución en las asimetrías de información, lo que implicaría un efecto oferta de menores restricciones en el acceso al crédito.

Estos dos factores son propuestos por Romano et al $(2000)^{1}$, al estudiar pequeñas empresas familiares en Australia. Acá se hacen extensivos a las pequeñas empresas en general. Los siguientes dos factores son aportes originales de este trabajo:

-La profesionalización del management, en especial en el campo de las ciencias económicas, puede esperarse que esté relacionado con el grado de diversificación de las fuentes de financiamiento. Existen numerosas fuentes de financiamiento no tradicionales que

\footnotetext{
${ }^{1}$ Las derivaciones sobre el efecto de la experiencia en crédito a nivel personal son aporte de esta investigación.
} 
frecuentemente son desconocidas por los empresarios PyMEs, a veces por falta de información, o simplemente ausencia de interés en el tema. En el mismo sentido actuaría que el administradorpropietario sea profesional del área. También se considera como parte de la profesionalización el empleo formal de métodos de planificación ${ }^{2}$, que se espera reduzca la opacidad informativa, y por lo tanto se relacione positivamente con el empleo de deuda.

- Los costos de quiebra personales, que son una consecuencia del entrelazamiento empresa-empresario. Estos incluyen las consecuencias socio-económicas y emocionales que la quiebra significa para el propietario, aún con responsabilidad limitada, y son el resultado de la falta de diversificación del patrimonio y capital humano del propietario, así como la unión emocional con la empresa, en especial si es un negocio familiar.

Por otra parte, se proponen dos enfoques de ciclo de vida, los cuales describen las características cambiantes en el tiempo de la empresa y sus propietarios-administradores.

- El ciclo de vida del administrador-propietario implica que la edad del propietario incide en las decisiones de financiamiento, ya que cambian su aversión al riesgo y a las pérdidas, sus costos personales de quiebra, y sus objetivos con respecto a la empresa, que varían de buscar crecimiento o rentabilidad, a fines más personales como mantener el estilo de vida y el ingreso de la familia. Se espera que el ciclo financiero de la empresa (Berger y Udell, 1998) y el ciclo de vida del propietario estén interconectados, a veces con efectos contrarios. Por ejemplo, las asimetrías de información disminuirían con la permanencia de la empresa en el negocio, derivando en mejor acceso a la deuda (efecto oferta), mientras que la aversión al riesgo y costos de quiebra personales aumentarían con la edad del empresario, implicando menor deseo de emplear deuda (efecto demanda).

\footnotetext{
${ }^{2}$ Esta forma operativa de la variable es considerada por Romano et al (2000).
} 
- El ciclo de vida de la empresa familiar propone que la naturaleza familiar y la generación que administra el negocio inciden en las decisiones de financiamiento. Gallo, Tàpies y Cappuyns (2004) indican que los negocios familiares tenderían a emplear menos deuda que sus contrapartes por aversión al riesgo financiero y el temor a la pérdida de control. Además, se pueden reconocer tres etapas distintivas de la empresa familiar (Gallo, 1998): el fundador-propietario, la segunda generación (hermanos como socios) y la tercera generación (primos y familiares como partícipes). La forma en que el ciclo de vida de empresa familiar se relaciona con el endeudamiento resulta especialmente compleja, ya que estarían actuando diversos factores: la propensión al riesgo de los administradores (Ang, 1991), los costos de agencia del capital propio y los costos personales de quiebra.

Por un lado, Ang (1991) indica que los propietarios de la primera generación serían más emprendedores y estarían dispuestos a tomar riesgos, características no necesariamente transmisibles a las generaciones posteriores. Además, consideramos que a medida que más personas participan de la propiedad de la empresa, aumentarían los costos de agencia del capital propio (por diferencias de intereses) y los costos personales de quiebra (ya que hay más capital humano comprometido), llevando el primer efecto a mayor endeudamiento, y el segundo, a menor. La inclusión de nuevos familiares en puestos gerenciales provocaría también mayores costos fijos, y posibles ineficiencias en la estructura de gestión, asociadas a mayores necesidades de financiamiento.

El efecto neto esperado es que, controlando por los costos personales de quiebra, los mayores costos de agencia del capital 
propio primen sobre la mayor aversión al riesgo, y lleven a que las generaciones no fundadoras empleen más deuda.

En el Cuadro 6 se resumen las hipótesis relativas al efecto esperado de las variables explicativas sobre la probabilidad de emplear pasivos financieros.

Cuadro 6 - Hipótesis de investigación sobre las variables que afectan la probabilidad de emplear pasivos financieros.

\begin{tabular}{|c|l|c|}
\hline$H$ & Variables explicativas & $\begin{array}{c}\text { Probabilidad } \\
\text { de PF=1 }\end{array}$ \\
\hline $1 \mathrm{a}$ & Empresa familiar & - \\
\hline $1 \mathrm{~b}$ & Generación de la empresa familiar & + \\
\hline 2 & Profesionalización del management & + \\
\hline 3 & Edad del empresario & - \\
\hline 4 & Objetivo empresario & + \\
\hline 5 & Costos personales de quiebra & + \\
\hline 6 & Actitud con respecto al endeudamiento & + \\
\hline
\end{tabular}

Fuente: Elaboración propia

II.2. Definiciones operativas y variables de control

- Edad del dueño: Es una variable cuantitativa, en caso de existir varios propietarios, o dos generaciones, se considera el de mayor edad.

- Empresa familiar: Para esta variable existen dos dimensiones: 
i. ¿Es empresa familiar? Como enfoque práctico Gallo (1997) considera que una empresa es familiar si se cumplen las siguientes características:

a) Propiedad: Una parte de la misma, con frecuencia la mayoría, pertenece a una familia que puede así ejercer el control de la actividad empresarial.

b) Poder: Alguno o varios de los propietarios dedican la totalidad, o una parte importante de su tiempo, a trabajar en le empresa.

c) Continuidad: Al menos está incorporada la segunda generación, como manifestación práctica de una clara intencionalidad de la familia propietaria de transmisión con éxito de la empresa hacia generaciones futuras.

Se considera a una empresa como familiar si se cumplen al menos las condiciones de propiedad y poder. Es una variable binaria, donde el uno corresponde a empresa familiar.

ii. Generación que la administra: si está presente más de una generación, se considera a la más antigua. Se codifica como variable binaria, se asigna un cero si administra la generación fundadora, y un uno en caso de que sea la segunda, tercera (u otra) generación.

-Profesionalización: Se emplean distintos caminos para medir este factor:

- Si el dueño tiene título universitario.

- Si el dueño es profesional de ciencias económicas.

- Si alguno de sus empleados es profesional de ciencias económicas (no se incluye en este caso el estudio contable externo).

- La realización de planificación escrita.

Las cuatro variables mencionadas son binarias, donde el uno denota presencia de la característica mencionada. 
- Actitud frente al endeudamiento y experiencia personal: Si el propietario emplea créditos personales para adquirir activos personales se codifica con un uno.

- Objetivos del propietario - administrador: Se considera que se persigue un objetivo empresario cuando el administradorpropietario declara que su principal objetivo con respecto a la empresa es el crecimiento en las ventas o el incremento del valor de su negocio. En este caso la variable toma valor uno. Si el objetivo principal es de tipo personal, como dar trabajo a los miembros de la familia, generar ingresos para la familia o asegurar la sucesión del negocio, la variable toma valor cero.

- Costos de quiebra personales: En este punto se busca distinguir si el costo más importante de una potencial quiebra sería económico (por ejemplo encontrar una nueva fuente de ingresos) o emocional (por ejemplo la reacción del entorno cercano o la sociedad), asignando un uno si la respuesta apunta a esto último.

Como los factores listados anteriormente no son los únicos que se espera influyan en el empleo de pasivos financieros, se emplean también una serie de variables de control que provienen del marco teórico. A continuación se indica la definición operativa de cada variable, junto con el efecto esperado sobre la probabilidad de emplear pasivos financieros.

- Tasa legal de impuestos: En principio se buscó medir este factor mediante la tasa impositiva correspondiente a la forma legal de la empresa, y en el caso de que correspondiese, a los socios o empresario unipersonal, preguntándose si es monotributista ${ }^{3}$. Durante la realización del relevamiento se observó que gran parte de los encuestados desconocía, o no deseaba informar, la tasa impositiva correspondiente. Entonces, a fines del análisis econométrico se buscó captar este factor indirectamente, a través de la forma legal.

${ }^{3}$ En la muestra obtenida no hay empresas monotributistas. 
- Estructura societaria: Se crearon ocho categorías para las distintas formas societarias, y una más para las empresas unipersonales. A fines del análisis estadístico, se ha operativizado esta variable como una dummy que toma valor uno si la forma legal implica responsabilidad limitada, y cero en caso contrario. Además de la limitación de la responsabilidad, esta variable estaría captando también el efecto del sistema de impuesto a las ganancias, ya que las formas legales que limitan la responsabilidad van en general acompañadas de una alícuota fija del impuesto (35\%), mientras que ésta es progresiva para las formas sin limitación, en las cuales tributa el socio. Otro efecto que también es captado por esta variable es la obligatoriedad de llevar estados contables para las sociedades con responsabilidad limitada. Bajo el enfoque de las asimetrías de información, el empleo de un sistema de información ordenado como es la contabilidad puede verse como una disminución de la opacidad informativa de la empresa frente a los proveedores de fondos externos. Bajo las tres relaciones expuestas, se espera un efecto positivo de la limitación de la responsabilidad en la probabilidad de emplear pasivos financieros.

- Sector: Se emplean cuatro sectores: industria, comercio, servicios y otros (agropecuario y construcción), resultando en tres variables dummy, siendo industria la categoría base. Con esta variable se busca captar el efecto de la estructura de los activos: tangibilidad, singularidad y madurez. Se espera una relación positiva entre tangibilidad (sector industria) y empleo de pasivos financieros, ya que este tipo de activos pueden servir como colateral, atenuando costos de quiebra y costos de agencia con los acreedores.

- Tamaño: A fines del análisis estadístico, se operativiza el tamaño en función de las ventas anuales sin IVA por sector, en una variable categórica que clasifica a las empresas en micro, pequeñas, medianas $\mathrm{y}$ grandes siguiendo las resoluciones 
675/2002 y 303/2004 de la Secretaría de la Pequeña y Mediana Empresa y Desarrollo Regional. Se emplean dos variables dummy (ventas pequeña y ventas mediana), siendo la categoría base la microempresa. Se espera una relación positiva del tamaño con el empleo de pasivos financieros, ya que los costos de quiebra directos serían mayormente fijos, y su incidencia sería menor con el tamaño. Además, se espera que las asimetrías de información sea mayores para las empresas pequeñas, aumentando los costos indirectos de quiebra, y los problemas de agencia serían mayores, implicando un menor empleo de pasivos financieros.

- Antigüedad de la empresa: Se espera que las asimetrías de información sean mayores para las empresas más jóvenes, por lo cual emplearían apalancamiento financiero en menor grado.

- Crecimiento: Se considera tanto el crecimiento histórico (últimos dos años) como el esperado (próximos dos años), medido como la variación en el volumen físico de ventas. Ambas son variables cuantitativas. Por el lado del trade off se espera una relación negativa con el endeudamiento, ya que las oportunidades de crecimiento se asocian con mayor riesgo moral. Sin embargo, la predicción de la jerarquía es de una relación positiva, ya que mayores oportunidades de crecimiento implican mayor necesidad de financiamiento.

- Rentabilidad: Es una variable cuantitativa, medida como la utilidad neta sobre ventas. En principio es una medida parcial de la rentabilidad, siendo preferible el rendimiento sobre la inversión porque incluye el efecto de la rotación. Sin embargo, resulta generalmente difícil para los empresarios PyME cuantificar la rentabilidad sobre los activos, por lo cual hemos preferido la medida que manejan con más frecuencia, el margen sobre ventas. Siguiendo los argumentos del trade off, bajo un esquema progresivo del impuesto a las ganancias el efecto de la rentabilidad en el endeudamiento sería positivo. En cambio, la 
jerarquía financiera predice que empresas rentables, que tienen mayor capacidad de autofinanciarse, emplearán menos deuda.

- Plazo del pasivo con proveedores: Petersen y Rajan (1994), entre otros autores, plantean que el crédito comercial surge como el sustituto costoso de los pasivos financieros, para aquellas empresas que enfrentan racionamiento del crédito financiero. Se busca incluir este efecto en una variable cuantitativa que es el plazo promedio de pago a proveedores, que toma valor cero si no se emplea esta fuente. Se espera una relación negativa con el empleo de pasivos financieros.

\section{II.3. Datos y método econométrico}

El empleo de pasivos financieros (H 1 a 6) se modela como un probit (modelo binario). El Prof. D. Garson ${ }^{4}$ indica que, en principio, se debería usar la regresión logística si la variable latente es cualitativa (ya que el logit emplea la distribución binomial), y el probit si se asume que la variable latente es cuantitativa (ya que el probit emplea la distribución normal), si bien la mayoría de las veces las conclusiones no variarán entre los dos modelos. Como en este caso la variable latente puede interpretarse como la estructura cuantitativa de financiamiento (el ratio Pasivos financieros/ Activos), resulta preferible el modelo probit.

El enfoque binario ha sido poco usado en la investigación aplicada del financiamiento de pequeñas empresas, y se ha encontrado sólo dos estudios previos que emplean este método en la Argentina: Filippo et al (2004) y Bebczuck (2004), quienes

\footnotetext{
${ }^{4}$ Dr. David Garson, College of Humanities and Social Sciences, North Carolina State University, en http://www2.chass.ncsu.edu/garson/pa765/logit.htm\#logitvsprobit
} 
emplean una regresión logística (logit) para estimar la probabilidad de una empresa de acceder a un crédito bancario. Este estudio difiere con éstos en que no se asume que no empleo equivale a no acceso, además de englobar en pasivos financieros a los que el propietario toma a nivel personal y aplica a la empresa.

A fines de contrastar empíricamente las hipótesis de investigación derivadas del enfoque propuesto, se realizó un estudio de campo en 140 empresas de la ciudad de Bahía Blanca, durante el periodo julio-octubre 2006. Para definir el universo de la muestra se consideró como definición de PyME a las Resoluciones 675/2002 y 303/2004 de la Sub -secretaría de la Pequeña y Mediana Empresa y Desarrollo Regional.

En el partido de Bahía Blanca existen, según los datos preliminares del Censo Económico, 9.710 locales que iniciaron sus actividades antes del 31/12/2004, de los cuales 9.663 se dedican a la producción de bienes y servicios, y el resto son UTEs, transporte y construcción. Estos constituyen el 2,81\% de los locales de la provincia de Buenos Aires, y el 0,932\% de los locales nacionales. De estos locales ubicados en Bahía Blanca, el 12,83\% posee más de 5 empleados: 1.246 empresas.

Dentro de estas empresas están incluidas también las grandes empresas radicadas en el partido de Bahía Blanca, las sucursales de grandes empresas (nacionales y multinacionales) y entidades financieras. Como los datos provisionales del CNE no permiten realizar esta discriminación, se recurrió a otras fuentes de información para estimar con mayor exactitud el tamaño de la población de interés.

Partiendo de la información contenida en el padrón de grandes contribuyentes de la Tasa de seguridad e higiene de la 
Municipalidad de Bahía Blanca, se identificaron 131 organizaciones que están fuera de la población objetivo, por ser grandes empresas locales, o sucursales de grandes empresas nacionales o internacionales, instituciones financieras, o entidades sin fines de lucro. Asimismo, se excluyeron las compañías de transporte público porque sus características de financiamiento, con participación significativa de subsidios estatales, difieren del promedio de las PyME, que no reciben en general subsidios directos. De esta forma se llegó a una estimación del tamaño de la población bajo estudio de 1.115 empresas.

Para determinar el tamaño de la muestra, se consideró como objetivo medir la proporción de empresas que emplean fondos de instituciones financieras en su estructura de financiamiento, mediante un muestreo aleatorio simple. Empleando un nivel de confianza de $90 \%$, y un error de 6,2\%, se obtuvo un tamaño de muestra de 150 empresas. En la muestra realizada se obtiene como resultado que el $51,8 \%{ }^{5}$ de las empresas emplean pasivos financieros distintos al giro en descubierto.

Se confeccionó un padrón de empresas a encuestar, partiendo del padrón de grandes contribuyentes de la Tasa de seguridad e higiene, que después del procesamiento descrito previamente se redujo a 218 firmas. Este listado se amplió con un grupo de 138 empresas elegidas aleatoriamente del Directorio de empresas publicado por la Subdirección Estadística de la Municipalidad de Bahía Blanca ${ }^{6}$.

Para la recolección de datos se utilizó como instrumento un cuestionario estructurado de preguntas cerradas a completarse

\footnotetext{
5 Sobre un total de 139 respuestas.

6 El mismo puede accederse en:

http://www.bahiablanca.gov.ar/empresario/listaempresa.html
} 
mediante entrevista personal. El mismo se compone de dos secciones: información general y la decisión de financiamiento, siendo el tiempo medio para la realización del mismo de 40 minutos. Para la medición de los distintos aspectos de la estructura de financiamiento se emplearon preguntas de validación, a fines de detectar inconsistencias en las respuestas.

Del padrón final de 356 empresas fueron contactadas 265, obteniéndose 143 respuestas válidas ${ }^{7}$. Esto arroja una tasa de respuesta del 54\%. Como tres de estas empresas resultan clasificadas como grandes, finalmente se inicia el procesamiento de los datos con 140 empresas. Del total de las entrevistas realizadas, 109 fueron completadas por el administradorpropietario, y el resto por encargados de la firma. Teniendo en cuenta el problema de datos faltantes, las estimaciones se realizan con los casos completos, sobre 80 a 100 empresas.

Como forma de validación externa, y a fines de contrastar nuestros resultados locales con otros de alcance nacional, en Rotstein, Briozzo, Esandi y Milanesi (2007) se comparan los resultados obtenidos con lo reportado por el Observatorio PyME en su informe estructural $2007^{8}$ (cuando la información está disponible), si bien estos datos incluyen únicamente firmas industriales.

7 De las cuales el $65 \%$ corresponde a empresas del padrón de grandes contribuyentes de la Tasa de seguridad e higiene.

8 Dicho informe puede descargarse en http://www.observatoriopyme.org.ar. 


\section{RESULTADOS}

III 1. Estadística descriptiva

Como introducción al estudio empírico primero se separa a las empresas en aquellas que usan pasivos financieros y aquellas que no, calculando las medias de cada variable explicativa propuesta sobre esa sub-muestra en el Cuadro $7^{9}$. El objetivo de este análisis es estudiar a primera vista si las empresas que emplean pasivos financieros difieren de las que no, y si esta diferenciación ocurre en el sentido esperado.

En el Cuadro 7 puede observarse que todas las variables se diferencian en el sentido esperado, excepto para empresa familiar. Las diferencias son estadísticamente significativas para la edad del propietario, el empleo de créditos personales y el empleo de planificación formal.

${ }^{9}$ La tabla se lee como sigue: de las 52 empresas que usan pasivos financieros (usapf $=1$ ), el $90 \%$ son familiares, el 53,8\% tienen un objetivo empresario, etc. De las 47 empresas que no usan pasivos financieros (usapf $=0$ ), el $83 \%$ son familiares, el 42,5\% tienen un objetivo empresario, etc. 
Cuadro 7- Características de las empresas que emplean pasivos financieros frente a las que no ${ }^{10}$.

\begin{tabular}{|l|c|c|c|}
\hline \multicolumn{1}{|c|}{ Variables } & Usapf=1 (52) & $\begin{array}{c}\text { Usapf=0 } \\
(47)\end{array}$ & Unidad \\
\hline Edad dueño & 46,8 & 50 & años \\
\hline Usa créditos personales & $30,7 \%$ & $12,7 \%$ & $\begin{array}{c}\% \text { de la } \\
\text { submuestra }\end{array}$ \\
\hline Empresa familiar & $90 \%$ & $83 \%$ & id \\
\hline Objetivo empresario & $53,8 \%$ & $42,5 \%$ & id \\
\hline Dueño prof. Cs. ec & $15,7 \%$ & $10,6 \%$ & id \\
\hline Planificación & $57,7 \%$ & $51 \%$ & id \\
\hline Empleados prof. Cs. Ec. & $19 \%$ & $17 \%$ & id \\
\hline Quiebra emocional & $27 \%$ & $32 \%$ & id \\
\hline
\end{tabular}

Fuente: Elaboración propia

En el Cuadro 8 se presenta un análisis análogo al anterior, para las variables de control. Las diferencias son estadísticamente significativas para el tamaño y la forma legal con responsabilidad limitada.

\section{III.2. Resultados del Probit}

En el Cuadro $9^{11}$ se muestran los efectos marginales para distintas especificaciones del modelo, a fines de verificar la robustez de los resultados. Éstos representan el cambio en la probabilidad de la variable dependiente, con el resto de las variables en sus valores medios. Entre paréntesis se informan los p-values, los cuales se muestran en todos los casos tal cual son

\footnotetext{
${ }^{10}$ Sobre las 99 empresas con datos completos sobre las cuales se realizan las estimaciones posteriores.

${ }^{11}$ Estimaciones obtenidas con Stata 7.0 empleando el comando dprobit Los valores corresponden al test LM. P-values a 2 colas.
} 
reportados por el programa. Para las variables dummy, se reporta el efecto de pasar de $\mathrm{d}=0$ a d=1.

Las estimaciones fueron hechas empleando los estimadores Huber/White/sandwich para la matriz de varianzas. Estos estimadores proveen errores estándar correctos aún si el modelo ha sido erróneamente especificado, en este caso, si el modelo correcto fuera el Logit, cuando se ha empleado el Probit para estimarlo ${ }^{12}$.

Los efectos significativos se encuentra señalados con asteriscos, $* *$ indica significatividad al 0,01, y* al 0,05. Resultan significativas las variables Edad del empresario, Crédito personal, Ventas pequeña (excepto M3), Ventas mediana, Limita responsabilidad y Sector otros (sólo M2, 4 y 6). Los signos se corresponden con los esperados.

Se ensayó como variable de control el crecimiento, tanto histórico como esperado. La inclusión de esta variable provoca fuertes inconvenientes en la estimación de máxima verosimilitud, llevando unas 19 iteraciones. Ambas medidas de crecimiento resultan no significativas, presentando el crecimiento histórico siempre signo negativo, y el esperado, signo positivo.

12 Long y Freese (2001), pág. 70. La estimación se realiza agregando la opción robust. 
Cuadro 8 - Características de las empresas que emplean pasivos financieros frente a las que no

\begin{tabular}{|l|c|c|c|}
\hline Controles & Usapf=1 & Usapf=0 & Unidad \\
\hline Tamaño: micro & $20 \%$ & $41 \%$ & $\%$ de la submuestra \\
\hline $\begin{array}{l}\text { Antigüedad } \\
\text { empresa }\end{array}$ & 23,8 & 25,7 & años \\
\hline $\begin{array}{l}\text { Responsab. } \\
\text { limitada }\end{array}$ & $69,2 \%$ & $42,5 \%$ & $\%$ de la submuestra \\
\hline Servicios & $19,2 \%$ & $19,1 \%$ & id \\
\hline Comercio & $59,6 \%$ & $61,7 \%$ & id \\
\hline Otros & $3,8 \%$ & $8,5 \%$ & id \\
\hline Industria & $17,4 \%$ & $10,7 \%$ & id \\
\hline $\begin{array}{l}\text { Crecimiento } \\
\text { esperado }\end{array}$ & $15,1 \%$ & $11,1 \%$ & $\begin{array}{c}\text { Tasa de variación de } \\
\text { las ventas en volumen } \\
\text { físico, } \\
\text { próximos 2 años }\end{array}$ \\
\hline $\begin{array}{l}\text { Crecimiento } \\
\text { histórico }\end{array}$ & $26,2 \%$ & $19,6 \%$ & $\begin{array}{c}\text { Tasa de variación de } \\
\text { las ventas en volumen } \\
\text { físico, } \\
\text { últimos 2 años }\end{array}$ \\
\hline $\begin{array}{l}\text { Plazo } \\
\text { proveedores }\end{array}$ & 31 & 33,6 & $\begin{array}{c}\text { Margen neto sobre } \\
\text { ventas }\end{array}$ \\
\hline $\begin{array}{l}\text { Margen sobre } \\
\text { ventas }\end{array}$ & $15,3 \%$ & $14,8 \%$ & \begin{tabular}{c} 
días \\
\hline
\end{tabular}
\end{tabular}

Fuente: Elaboración propia 
Cuadro 9.A- Estimaciones del modelo PROBIT (efectos marginales). Variables explicativas

\begin{tabular}{|c|c|c|c|c|c|c|}
\hline V.explicat. & M1 & M2 & M3 & M4 & M5 & M6 \\
\hline $\begin{array}{l}\text { Costos } \\
\text { quiebra } \\
\text { emociona- } \\
\text { les }\end{array}$ & $(0.858)$ & $\begin{array}{l}-0.051 \\
(0.671) \\
\end{array}$ & $(0.858)$ & $(0.600)$ & $(0.890)$ & $\begin{array}{r}-0.068 \\
(0.578) \\
\end{array}$ \\
\hline $\begin{array}{l}\text { Objetivo } \\
\text { empresario }\end{array}$ & $\begin{array}{l}-0.021 \\
(0.880) \\
\end{array}$ & $\begin{array}{l}-0.069 \\
(0.584) \\
\end{array}$ & $\begin{array}{l}-0.080 \\
(0.554) \\
\end{array}$ & $\begin{array}{l}-0.084 \\
(0.509)\end{array}$ & $\begin{array}{l}-0.050 \\
(0.712) \\
\end{array}$ & $\begin{array}{l}-0.073 \\
(0.567) \\
\end{array}$ \\
\hline $\begin{array}{l}\text { Edad del } \\
\text { empresario }\end{array}$ & $\begin{array}{c}-0.014 \\
(0.035)^{*}\end{array}$ & $\begin{array}{c}-0.013 \\
(0.024) *\end{array}$ & $\begin{array}{c}-0.012 \\
(0.047)^{*}\end{array}$ & $\begin{array}{c}-0.012 \\
(0.025)^{*}\end{array}$ & $\begin{array}{l}-0.012 \\
(0.053) \\
\end{array}$ & $\begin{array}{c}-0.013 \\
(0.021) *\end{array}$ \\
\hline $\begin{array}{l}\text { Planifica } \\
\text { por escrito }\end{array}$ & $\begin{array}{c}-0.151 \\
(0.313) \\
\end{array}$ & $\begin{array}{l}-0.029 \\
(0.821) \\
\end{array}$ & & & & \\
\hline $\begin{array}{l}\text { Dueño Prof. } \\
\text { de Cs. Ec }\end{array}$ & & & $\begin{array}{c}0.282 \\
(0.107) \\
\end{array}$ & $\begin{array}{c}0.097 \\
(0.535) \\
\end{array}$ & & \\
\hline $\begin{array}{l}\text { Empleados } \\
\text { Cs Ec. }\end{array}$ & & & & & $\begin{array}{l}-0.169 \\
(0.356) \\
\end{array}$ & $\begin{array}{l}-0.138 \\
(0.366) \\
\end{array}$ \\
\hline $\begin{array}{l}\text { Usa crédito } \\
\text { personal }\end{array}$ & $\begin{array}{c}0.375 \\
(0.008) * *\end{array}$ & $\begin{array}{c}0.304 \\
(0.018)^{*}\end{array}$ & $\begin{array}{c}0.308 \\
(0.038)^{*} \\
\end{array}$ & $\begin{array}{c}0.298 \\
(0.021)^{*}\end{array}$ & $\begin{array}{c}0.339 \\
(0.018)^{*}\end{array}$ & $\begin{array}{c}0.303 \\
(0.018) *\end{array}$ \\
\hline $\begin{array}{l}\text { Empresa } \\
\text { familiar }\end{array}$ & $\begin{array}{c}0.199 \\
(0.443) \\
\end{array}$ & $\begin{array}{c}0.324 \\
(0.103)\end{array}$ & $\begin{array}{c}0.279 \\
(0.333)\end{array}$ & $\begin{array}{c}0.334 \\
(0.101)\end{array}$ & $\begin{array}{c}0.244 \\
(0.375)\end{array}$ & $\begin{array}{c}0.348 \\
(0.094)\end{array}$ \\
\hline
\end{tabular}

Como la variable rentabilidad presenta numerosos datos faltantes, y resulta no significativa, se ensayan formulaciones excluyéndola, a fines de observar el efecto de incorporar más observaciones. 
Cuadro 9.B- Estimaciones del modelo PROBIT (efectos marginales). Variables de control

\begin{tabular}{|l|c|c|c|c|c|c|}
\hline V. control & $\mathrm{M} 1$ & $\mathrm{M} 2$ & $\mathrm{M} 3$ & $\mathrm{M} 4$ & $\mathrm{M} 5$ & $\mathrm{M} 6$ \\
\hline $\begin{array}{l}\text { Ventas } \\
\text { pequeña }\end{array}$ & $\begin{array}{c}0.289 \\
(0.043)^{*}\end{array}$ & $\begin{array}{c}0.277 \\
(0.032)^{*}\end{array}$ & $\begin{array}{c}0.327 \\
(0.025)^{*}\end{array}$ & $\begin{array}{c}0.288 \\
(0.027)^{*}\end{array}$ & $\begin{array}{c}0.316 \\
(0.027)^{*}\end{array}$ & $\begin{array}{c}0.297 \\
(0.022)^{*}\end{array}$ \\
\hline $\begin{array}{l}\text { Ventas } \\
\text { mediana }\end{array}$ & $\begin{array}{c}0.471 \\
(0.068)\end{array}$ & $\begin{array}{c}0.428 \\
(0.034)^{*}\end{array}$ & $\begin{array}{c}0.442 \\
(0.104)\end{array}$ & $\begin{array}{c}0.419 \\
(0.046)^{*}\end{array}$ & $\begin{array}{c}0.476 \\
(0.064)\end{array}$ & $\begin{array}{c}0.438 \\
(0.032)^{*}\end{array}$ \\
\hline $\begin{array}{l}\text { Plazo } \\
\text { crédito } \\
\text { proveedores }\end{array}$ & -0.002 & -0.001 & -0.003 & -0.001 & -0.003 & -0.001 \\
\hline $\begin{array}{l}\text { Limita } \\
\text { responsabili } \\
\text { dad }\end{array}$ & $\begin{array}{c}0.499) \\
(0.000)^{* *}\end{array}$ & $\begin{array}{c}0.426 \\
(0.001)^{* *}\end{array}$ & $\begin{array}{c}0.427 \\
(0.002)^{* *}\end{array}$ & $\begin{array}{c}0.414 \\
(0.001)^{* * *}\end{array}$ & $\begin{array}{c}0.450 \\
(0.001)^{* * *}\end{array}$ & $\begin{array}{c}0.435 \\
(0.001)^{* *}\end{array}$ \\
\hline $\begin{array}{l}\text { Antigüedad } \\
\text { empresa }\end{array}$ & $\begin{array}{c}-0.001 \\
(0.699)\end{array}$ & $\begin{array}{c}-0.003 \\
(0.394)\end{array}$ & $\begin{array}{c}-0.002 \\
(0.568)\end{array}$ & $\begin{array}{c}-0.003 \\
(0.362)\end{array}$ & $\begin{array}{c}-0.002 \\
(0.559)\end{array}$ & $\begin{array}{c}-0.003 \\
(0.373)\end{array}$ \\
\hline $\begin{array}{l}\text { Sector } \\
\text { servicios }\end{array}$ & $\begin{array}{c}-0.202 \\
(0.383)\end{array}$ & $\begin{array}{c}-0.265 \\
(0.201)\end{array}$ & $\begin{array}{c}-0.193 \\
(0.404)\end{array}$ & $\begin{array}{c}-0.276 \\
(0.161)\end{array}$ & $\begin{array}{c}-0.190 \\
(0.416)\end{array}$ & $\begin{array}{c}-0.254 \\
(0.205)\end{array}$ \\
\hline $\begin{array}{l}\text { Sector } \\
\text { comercio }\end{array}$ & $\begin{array}{c}-0.186 \\
(0.359)\end{array}$ & $\begin{array}{c}-0.232 \\
(0.212)\end{array}$ & $\begin{array}{c}-0.169 \\
(0.396)\end{array}$ & $\begin{array}{c}-0.238 \\
(0.194)\end{array}$ & $\begin{array}{c}-0.151 \\
(0.465)\end{array}$ & $\begin{array}{c}-0.218 \\
(0.238)\end{array}$ \\
\hline $\begin{array}{l}\text { Sector otros } \\
\text { (agrop y } \\
\text { constr) }\end{array}$ & $\begin{array}{c}-0.491 \\
(0.103)\end{array}$ & $\begin{array}{c}-0.544 \\
(0.020)^{*}\end{array}$ & $\begin{array}{c}-0.478 \\
(0.109)\end{array}$ & $\begin{array}{c}-0.543 \\
(0.018)^{*}\end{array}$ & $\begin{array}{c}-0.484 \\
(0.106)\end{array}$ & $\begin{array}{c}-0.534 \\
(0.030)^{*}\end{array}$ \\
\hline $\begin{array}{l}\text { Rentabili- } \\
\text { dad }\end{array}$ & $\begin{array}{c}1.024 \\
(0.197)\end{array}$ & & $\begin{array}{c}0.998 \\
(0.210)\end{array}$ & & $\begin{array}{c}0.803 \\
(0.289)\end{array}$ & \\
\hline $\begin{array}{l}\text { Observacio- } \\
\text { nes }\end{array}$ & 82 & 99 & 82 & 99 & 82 & 99 \\
\hline
\end{tabular}

Fuente: Elaboración propia

Primero se estudia el efecto de excluir la variable rentabilidad, estimando los modelos sin esta variable sobre el mismo conjunto de observaciones que los modelos que sí la 
incluyen. Así, las diferencias entre cada modelo y su variación se originan por la exclusión de la variable rentabilidad. Los cambios observados consisten en que la edad del empresario pierde significatividad en los modelos re-estimados de M2 y M4, si bien la magnitud del efecto presenta poca variación. Las variables de tamaño también pierden significatividad en los modelos reestimados, haciéndose débil en M4 y M6. Lo mismo ocurre con Ventas Mediana. En estos dos casos la variación en la magnitud del coeficiente es más importante. Por otra parte, el sector otros (agropecuario y construcción) presenta una significatividad débil en los modelos re-estimados de M2 y M4. Empleando el Criterio de Información Bayesiano (BIC y BIC') se obtiene evidencia positiva a favor de los modelos que incluyen la variable rentabilidad (Modelos 1, 3 y 5 en el Cuadro 9).

En segundo lugar se analiza el efecto de incorporar nuevas observaciones. Para esto se comparan las estimaciones de los modelos 2, 4 y 6 del Cuadro 9 sobre distintas muestras, de 82 y 99 datos. De esta forma, el cambio en las estimaciones se origina por la inclusión de 17 observaciones. Al pasar de 82 a 99 observaciones, la variable edad del empresario gana significatividad. Las variables ventas pequeña y mediana, y sector otros ganan significatividad en algunas de las estimaciones con más observaciones. Por otra parte, la variable Empresa familiar resulta débilmente significativa solo en el modelo 6 .

En resumen, para las dos variables explicativas de interés, se observa que:

-Edad del empresario: con 82 observaciones, la significatividad es mayor al incluir la variable rentabilidad como control. El signo siempre es negativo, acorde a lo esperado, y la magnitud del efecto presenta poca variación (rango $-0,10$ a -0,14). Excluyendo 
la variable rentabilidad, la variable gana significatividad al pasar de 82 a 99 datos (rango del efecto: $-0,10$ a $-0,13$ ).

-Empleo de crédito personal: la significatividad se reduce levemente al incluir la variable rentabilidad como control (rango del efecto: 0,297 a 0,347). Excluyendo la variable rentabilidad, la variable gana significatividad al pasar de 82 a 99 datos (rango del efecto igual al caso anterior).

Entonces, se puede concluir que las variables explicativas que resultan significativas tienen resultados robustos en las distintas estimaciones.

A fines de testear la hipótesis $1 \mathrm{~b}$ sobre el efecto de la generación de la empresa familiar, se estiman los modelos 7, 8 y 9, sólo para empresas familiares e incorporando la variable generación de la empresa familiar. En el Cuadro 10 se presentan los resultados (estimación robusta).

En el Cuadro 10 puede observarse que los signos de algunas de las variables que también resultaban significativas en el Cuadro 9 no presentan mayores variaciones en esta nueva estimación. Tal es el caso de uso de créditos personales, edad del empresario, y limitación de la responsabilidad. La nueva variable incluida, generación de la empresa familiar, no resulta significativa en los modelos 8 y 9 , y sí lo es pero débilmente para el modelo 7, con un signo contrario al esperado. Esto podría indicar que prevalece el efecto de la menor propensión emprendedora sobre el incremento de los costos de agencia. Las variables Ventas pequeña y Planificación resultan débilmente significativas en el Modelo 7, presentando esta última signo contrario al esperado. 
Cuadro 10.A - Estimaciones del modelo PROBIT (efectos marginales) sobre empresas familiares- Variables explicativas

\begin{tabular}{|l|c|c|c|}
\hline Variables explicativas & $\mathrm{M} 7$ & $\mathrm{M} 8$ & $\mathrm{M} 9$ \\
\hline Costos quiebra emocionales & $\begin{array}{c}-0.081 \\
(0.570)\end{array}$ & $\begin{array}{c}-0.080 \\
(0.581)\end{array}$ & $\begin{array}{c}-0.120 \\
(0.424)\end{array}$ \\
\hline Objetivo empresario & $\begin{array}{c}0.042 \\
(0.742)\end{array}$ & $\begin{array}{c}0.028 \\
(0.824)\end{array}$ & $\begin{array}{c}0.041 \\
(0.753)\end{array}$ \\
\hline Edad del empresario & $\begin{array}{c}-0.014 \\
(0.023)^{*}\end{array}$ & $\begin{array}{c}-0.012 \\
(0.048)^{*}\end{array}$ & $\begin{array}{c}-0.011 \\
(0.048)^{*}\end{array}$ \\
\hline Planifica por escrito & $\begin{array}{c}-0.248 \\
(0.075)\end{array}$ & & \\
\hline Empleados Cs Ec. & & & -0.203 \\
\hline Dueño Prof. de Cs. Ec & & $\begin{array}{c}-0.035 \\
(0.842)\end{array}$ & \\
\hline Usa crédito personal & $\begin{array}{c}0.385 \\
(0.005)^{* *}\end{array}$ & $\begin{array}{c}0.371 \\
(0.009)^{* *}\end{array}$ & $\begin{array}{c}0.378 \\
(0.006)^{* *}\end{array}$ \\
\hline Generación no fundadora & $\begin{array}{c}-0.234 \\
(0.084)\end{array}$ & $\begin{array}{c}-0.175 \\
(0.181)\end{array}$ & $\begin{array}{l}-0.192 \\
(0.143)\end{array}$ \\
\hline
\end{tabular}

Empleando el Likelihood ratio ${ }^{13}$ y el test de Wald se testea la hipótesis de que todos los coeficientes son simultáneamente cero. En el Cuadro 11 se resumen los resultados para las nueve especificaciones estimadas, para todas se rechaza la hipótesis nula (p-value inferior a 0,037$)^{14}$.

\footnotetext{
${ }^{13}$ Comando lrtest.

${ }^{14}$ Estimaciones realizadas sobre la muestra original.
} 
Como medidas del poder de predicción del modelo se calculan el porcentaje de aciertos $\left(\mathrm{R}^{2}\right.$ count $)$ y el $\mathrm{R}^{2}$ count ajustado. Los resultados se muestran en el Cuadro 12, donde puede advertirse que el modelo con mejor poder de predicción es M 3. Para las empresas familiares (M 7, 8 y 9) el poder de predicción es menor.

Cuadro 10 - Estimaciones del modelo PROBIT (efectos marginales) sobre empresas familiares- Variables de control.

\begin{tabular}{|l|c|c|c|}
\hline Variables de control & $\mathrm{M} 7$ & $\mathrm{M} 8$ & $\mathrm{M} 9$ \\
\hline Ventas pequeña & $\begin{array}{c}0.230 \\
(0.096)\end{array}$ & $\begin{array}{c}0.211 \\
(0.125)\end{array}$ & $\begin{array}{c}0.242 \\
(0.074)\end{array}$ \\
\hline Ventas mediana & $\begin{array}{c}0.255 \\
(0.254)\end{array}$ & $\begin{array}{c}0.147 \\
(0.511)\end{array}$ & $\begin{array}{c}0.209 \\
(0.387)\end{array}$ \\
\hline Plazo crédito proveedores & $\begin{array}{c}-0.002 \\
(0.442)\end{array}$ & $\begin{array}{c}-0.003 \\
(0.365)\end{array}$ & $\begin{array}{c}-0.003 \\
(0.298)\end{array}$ \\
\hline Limita responsabilidad & $\begin{array}{c}0.419 \\
(0.001)^{* *}\end{array}$ & $\begin{array}{c}0.360 \\
(0.005) * *\end{array}$ & $\begin{array}{c}0.368 \\
(0.003)^{* *}\end{array}$ \\
\hline Antigüedad empresa & -0.004 & -0.003 & -0.004 \\
$(0.271)$ & $(0.372)$ & $(0.291)$ \\
\hline Sector servicios & 0.110 & 0.036 & 0.061 \\
& $(0.578)$ & $(0.858)$ & $(0.755)$ \\
\hline Sector comercio ${ }^{15}$ & 0.023 & 0.019 & 0.029 \\
& $(0.888)$ & $(0.909)$ & $(0.862)$ \\
\hline Observaciones & 85 & 85 & 85 \\
\hline
\end{tabular}

Fuente: Elaboración propia

${ }^{15}$ El sector Otros se excluye de la estimación por no haber casos en la muestra correspondiente. 
Cuadro 11- Tests de significatividad conjunta (LR y Wald)

\begin{tabular}{|l|c|c|c|c|c|}
\hline Modelo & 1 & 2 & 3 & 4 & 5 \\
\hline LRX $^{2}$ & 26.396 & 31.488 & 28.134 & 31.764 & 26.143 \\
p-value & $(0.034)$ & $(0.005)$ & $(0.03)$ & $(0.004)$ & $(0.037)$ \\
\hline Wald & 28.03 & 30.87 & 28.57 & 30.27 & 29.74 \\
p-value & $(0.0214)$ & $(0.0058)$ & $(0.0182)$ & $(0.007)$ & $(0.0129)$ \\
\hline
\end{tabular}

\begin{tabular}{|l|c|c|c|c|}
\hline Modelo & 6 & 7 & 8 & 9 \\
\hline LRX $^{2}$ & 32.356 & 26.895 & 23.944 & 25.409 \\
p-value & $(0.006)$ & $(0.013)$ & $(0.032)$ & $(0.02)$ \\
\hline Wald & 30.75 & 31.72 & 28.65 & 32.6 \\
p-value & $(0.006)$ & $(0.0026)$ & $(0.0073)$ & $(0.002)$ \\
\hline
\end{tabular}

Fuente: Elaboración propia

Cuadro 12 - count $R^{2}$ y count $R^{2}$ ajustado

\begin{tabular}{|l|c|c|c|c|c|}
\hline Modelo & 1 & 2 & 3 & 4 & 5 \\
\hline count $\mathrm{R}^{2}$ & 0.72 & 0.697 & 0.756 & 0.707 & 0.744 \\
\hline count $\mathrm{R}^{2}$ aj. & 0.439 & 0.362 & 0.512 & 0.383 & 0.488 \\
\hline
\end{tabular}

\begin{tabular}{|l|c|c|c|c|}
\hline Modelo & 6 & 7 & 8 & 9 \\
\hline count $\mathrm{R}^{2}$ & 0.707 & 0.671 & 0.659 & 0.671 \\
\hline count $\mathrm{R}^{2}$ aj. & 0.383 & 0.317 & 0.293 & 0.317 \\
\hline
\end{tabular}

Fuente: Elaboración propia

Long (1997) advierte que para este tipo de modelos, que se estiman por máxima verosimilitud, es recomendable emplear muestras grandes para poder confiar en las propiedades de los estimadores. Por este motivo se prueban distintas especificaciones que permiten aprovechar mejor los datos disponibles. De todas formas, Long señala que los métodos de estimación numéricos tienden a funcionar bien cuando el modelo es apropiado para los datos, en cuyo caso debería lograrse la convergencia en unas cinco iteraciones. Para todos los modelos que se estiman, la 
convergencia se logra, según el caso, con cuatro o cinco iteraciones.

\section{III.3. Extensiones a la intepretación del Probit}

Como el modelo Probit no es lineal, el efecto marginal estimado en los Cuadros 9 y 10 puede resultar insuficiente para comprender en profundidad el efecto de una variable. En esta sección se amplía la interpretación del efecto de las variables significativas, tomando como base en el modelo 2 del Cuadro 9.

Primero se estima el efecto de cada variable significativa en la probabilidad estimada, manteniendo el resto de las variables en sus valores medios. De esta forma se obtienen los resultados del Cuadro 13. Excepto la variable edad del empresario, el resto son variables dummy, por lo que el mínimo es cero y el máximo uno.

Cuadro 13 - Probabilidad de usar pasivos financieros según edad del propietario, uso de crédito personal

y limitación de responsabilidad

\begin{tabular}{|l|c|c|c|}
\hline Variable & $\begin{array}{c}\operatorname{Pr}(\mathrm{PF}=1) \text { en } \\
\text { Min }\end{array}$ & $\operatorname{Pr}(\mathrm{PF}=1)$ en Max & Rango de Prob. \\
\hline $\begin{array}{l}\text { Edad del } \\
\text { empresario }\end{array}$ & 0,8109 & 0,2129 & 0,598 \\
\hline $\begin{array}{l}\text { Usa crédito } \\
\text { personal }\end{array}$ & 0,4649 & 0,7689 & 0,304 \\
\hline $\begin{array}{l}\text { Limita } \\
\text { responsabilidad }\end{array}$ & 0,2941 & 0,7202 & 0,4261 \\
\hline
\end{tabular}

Fuente: Elaboración propia 
La probabilidad de emplear pasivos financieros en función del tamaño y el sector se muestra en el Cuadro $14{ }^{16}$.

Long (1997) advierte que la función de probabilidad es aproximadamente lineal en el rango 0,2 a 0,8 . Entonces, para evaluar el efecto de variables cuyo rango de probabilidad se encuentre entre estos valores pueden emplearse medidas simples, como el efecto marginal o discreto. Por lo tanto, las estimaciones del efecto marginal presentadas en los Cuadros 9 y 10 resultan apropiadas y suficientes para estudiar el efecto de las variables de interés. Para finalizar esta sección, la cuasi-linealidad de los efectos estimados puede observarse en los Gráficos 1 y 2.

Cuadro 14 - Probabilidad de usar pasivos financieros según el tamaño y sector

\begin{tabular}{|c|c|}
\hline Tamaño & $\operatorname{Pr}(\mathrm{PF}=1)$ \\
\hline Micro & 0,3302 \\
\hline Pequeña & 0,6064 \\
\hline Mediana & 0,8284 \\
\hline Sector & $\operatorname{Pr}(\mathrm{PF}=1)$ \\
\hline Industria & 0,76 \\
\hline Comercio & 0,54 \\
\hline Servicios & 0,51 \\
\hline Otros & 0,11 \\
\hline
\end{tabular}

Fuente: Elaboración propia

\footnotetext{
${ }^{16}$ Todas las variables en sus valores medios, excepto ventas y sector en función del efecto que se busca estimar.
} 
Se finaliza esta sección con un resumen general sobre los efectos esperados y observados en el Cuadro 15.

Gráfico 1- La probabilidad de emplear pasivos financieros según la edad del propietario y el empleo de crédito a nivel personal.

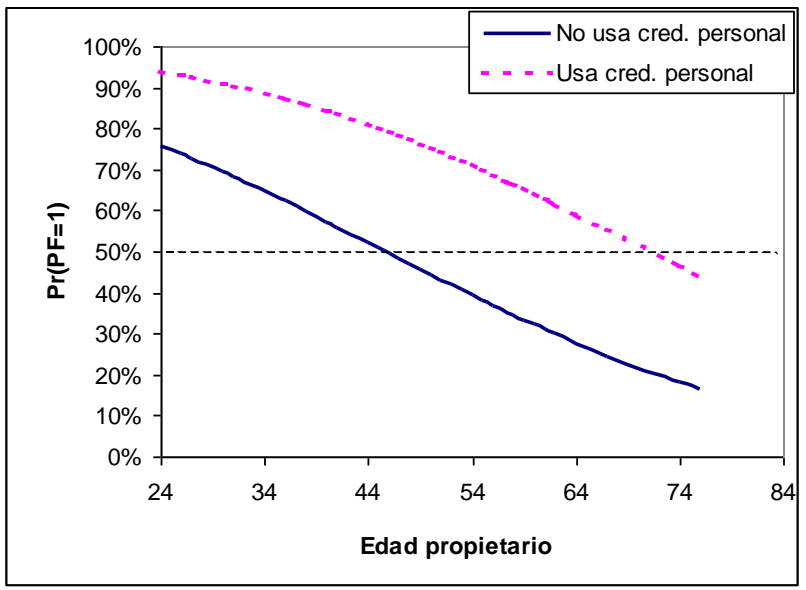

Gráfico 2 - La probabilidad de emplear pasivos financieros según la edad del propietario y la limitación de la responsabilidad.

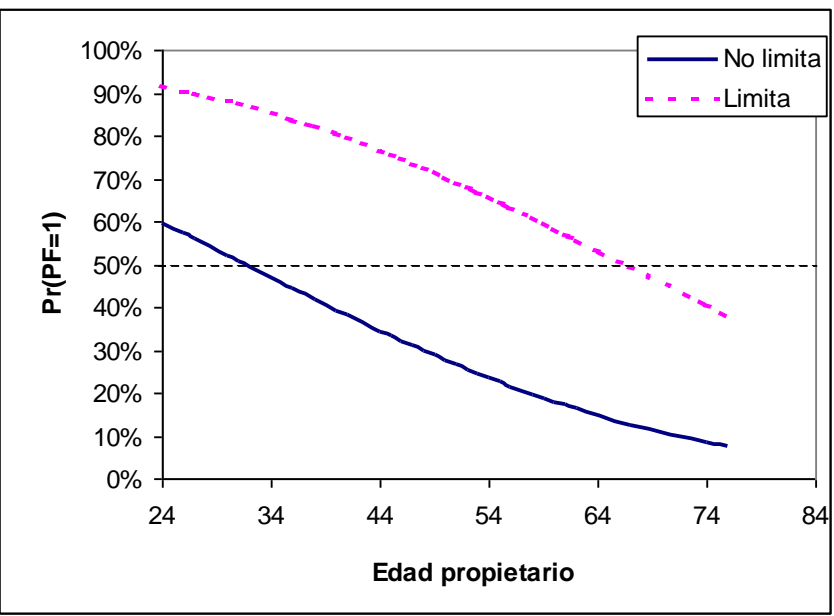




\section{Cuadro 15 - Resumen de efectos}

\begin{tabular}{|l|c|c|}
\hline Variables explicativas & Esperado & Observado \\
\hline Profesionalización del management & + & $\mathrm{ns}$ \\
\hline Edad del empresario & - & - \\
\hline Objetivo empresario & + & $\mathrm{ns}$ \\
\hline Costos quiebra emocionales & - & $\mathrm{ns}$ \\
\hline $\begin{array}{l}\text { Usa crédito personal (actitud frente al } \\
\text { endeudamiento) }\end{array}$ & + & + \\
\hline Empresa familiar & - & $\mathrm{ns}$ \\
\hline Generación de la empresa familiar & + & $\mathrm{ns}$ \\
\hline Variables control & & \\
\hline Tamaño & + & + \\
\hline Rentabilidad & $+/-$ & $\mathrm{ns}$ \\
\hline Antigüedad de la empresa & + & $\mathrm{ns}$ \\
\hline Crecimiento histórico & $+/-$ & $\mathrm{ns}$ \\
\hline Crecimiento esperado & $+/-$ & $\mathrm{ns}$ \\
\hline Sector industria & + & + \\
\hline Limitación de la responsabilidad & + & + \\
\hline Plazo crédito proveedores & - & $\mathrm{ns}$ \\
\hline
\end{tabular}

Fuente: Elaboración propia

\section{CONCLUSIONES}

1. Conclusiones sobre la contrastación de las hipótesis

- La naturaleza familiar (H1 a, H1b): No se encuentra evidencia que apoye la relación esperada entre la naturaleza familiar del negocio, y la generación de la empresa familiar, con la probabilidad de emplear pasivos financieros. En la revisión de la literatura empírica no se encontraron estudios que incluyeran estas variables, por lo cual no se cuenta con resultados previos. En resumen, la evidencia no apoya el enfoque propuesto del ciclo de vida de la empresa familiar. 
-Grado de profesionalización del management (H 2):La profesionalización del management resulta no significativa, para todas de las formas de operativizarla: si el propietario es profesional de ciencias económicas, si se emplean a este tipo de profesionales, o si se realiza planificación formal. Es decir, no se encuentra que afecte la probabilidad de emplear pasivos financieros, ni la actitud con respecto al endeudamiento de la empresa. El trabajo de Romano et al (2000) es el único antecedente empírico y teórico que emplea esta variable, para la forma de empleo de métodos de planificación formal, y aplicada sólo a empresas familiares. Encuentran que tiene un efecto positivo y significativo en el ratio de deuda. Como Romano et al (2000) miden intensidad de la estructura observada (ratio de apalancamiento), mientras que el presente estudio mide presenciaausencia, puede considerarse que si bien esta variable es relevante en el primer caso, esta relevancia no se refleja en la forma elegida aquí para la de medición. Una segunda consideración reside en la distinta localización de los estudios, ya que el trabajo de Romano et al (2000) fue realizado en Australia. En Argentina, Dapena y Dapena (2003) realizan un estudio sobre los sistemas de información y planificación de las PyMEs cordobesas, y concluyen que existe un importante déficit en estas áreas. Esta característica de las empresas argentinas puede no estar presente en sus pares australianas.

- Edad del dueño-administrador (H 3): La evidencia apoya la existencia de una relación negativa de la edad del empresario con la probabilidad de emplear pasivos financieros (con significatividad de 5\%). Solo Romano et al (2000) incluyen esta variable, que no resulta significativa en el ratio de endeudamiento enfocado a empresas familiares. En esta investigación resulta significativa según el efecto esperado tanto para la muestra general, como al restringir el estudio a empresas familiares. Este 
resultado apoya el enfoque propuesto del ciclo de vida del administrador-propietario. En particular, como se controla por los costos personales de quiebra y los objetivos con respecto a la empresa, el estudio estaría captando el efecto aislado del cambio en la aversión al riesgo y a las pérdidas con la edad. También se controla el efecto del ciclo financiero de la empresa, al incluir la antigüedad de la firma como regresor. En resumen, el resultado obtenido apoya la idea de que la aversión al riesgo y a las pérdidas aumenta con la edad, lo cual incide en las decisiones de financiamiento.

- Objetivo empresario (H4): No se encuentra evidencia de la incidencia de perseguir un objetivo empresario (aumentar el valor de la empresa o crecimiento en las ventas) en la probabilidad de emplear pasivos financieros. Entre los antecedentes empíricos, solo Romano et al (2000) incluyen esta variable como objetivo orientado al crecimiento, reportando un efecto positivo (solo empresas familiares) en el ratio de endeudamiento. En este punto caben las mismas consideraciones que con respecto a la profesionalización del management: Romano et al (2000) miden intensidad de la estructura observada (ratio de apalancamiento) en Australia, mientras que el presente estudio analiza presenciaausencia de endeudamiento financiero en primer lugar, $\mathrm{y}$ estructura deseada en segundo lugar.

- Costos de quiebra personales (H 5): No se encuentra evidencia de que los costos de quiebra personales se relacionen significativamente con la probabilidad de emplear pasivos financieros. No se ha encontrado antecedentes teóricos o empíricos referidos a esta variable.

- Actitud frente al endeudamiento y experiencia a nivel personal (H 6): La experiencia con deuda a nivel personal resulta 
significativa. Esta variable tiene un efecto positivo, significativo al 1\%, sobre la probabilidad de emplear pasivos financieros. No se cuenta con antecedentes empíricos referidos a esta variable, y únicamente Romano et al (2000) la enuncia como factor relevante, coincidiendo nuestros resultados con lo teóricamente esperado. La evidencia obtenida apoya nuevamente la relevancia del entrelazamiento empresa-propietario, como se planteó en la visión gerencial.

- Variables de control

A continuación se consideran los efectos observados de las variables de control en ambos modelos.

- Tamaño de la empresa (medido como ventas): Se encuentra evidencia de una relación positiva del tamaño con la probabilidad de emplear pasivos financieros, al pasar de micro a pequeña empresa, y de pequeña a mediana. La significatividad varía entre $1 \%$ y $10 \%$ con las distintas especificaciones. Los antecedentes empíricos emplean diversas variables para medir este factor, como ventas, valor contable de activos y número de empleados. El efecto sobre el ratio de endeudamiento predominantemente observado en los estudios citados es positivo ${ }^{17}$. Este resultado coincide con lo esperado según los costos de quiebra y asimetrías de información.

- Antigüedad de la empresa: No se encuentra que se relacione significativamente con la probabilidad de emplear pasivos financieros. Como en el caso de tamaño, la antiguiedad también es incluida en la mayoría de los antecedentes empíricos, observando un efecto negativo sobre el ratio de endeudamiento. Desde los

17 Ver tabla 5. 
enfoques teóricos tradicionales, la predicción sobre esta variable no es definitiva: la relación esperada tamaño-endeudamiento es positiva bajo el enfoque del trade off, tanto por la menor incidencia de los costos de quiebra como por los menores costos de agencia. Bajo el enfoque de la jerarquía financiera el efecto es indeterminado: la relación sería positiva si se considera que con la edad y tamaño disminuyen los costos de la selección adversa, y negativa si se considera que las empresas maduras generan mayor autofinanciamiento, y tienen menores necesidades de inversión.

- Rentabilidad: El efecto observado en los antecedentes empíricos es negativo. En este estudio no se encuentra evidencia de que sea significativo en la probabilidad de emplear pasivos financieros. El marco teórico no brinda consenso sobre el comportamiento esperado de esta variable: para el pecking order, la mayor disponibilidad de fondos propios generados por la empresa se deriva en menor empleo del financiamiento externo, manteniendo las necesidades de fondos constantes. En cambio, el trade off estático considera un esquema progresivo de la alícuota del impuesto a las ganancias y los costos de agencia de los flujos de fondos libres, para implicar una relación positiva con el endeudamiento. En el enfoque de trade off dinámico, con costos de ajuste, las empresas ajustarán su estructura hacia su ratio objetivo sólo si los beneficios generados por este ajuste exceden a los costos, por lo cual la predicción de la relación rentabilidadendeudamiento no es directamente predecible.

- Crecimiento: No se encuentra evidencia de una relación significativa del crecimiento (histórico y esperado) con la probabilidad de emplear pasivos financieros. En cuanto a los antecedentes empíricos, la mayoría de los trabajos reportan un efecto positivo en el ratio de endeudamiento. Los antecedentes teóricos no presentan un consenso en el efecto esperado: es 
negativo para el trade off, debido a costos de agencia y de quiebra, y positivo para la jerarquía financiera, por el requerimiento creciente de fondos.

- Plazo de crédito de proveedores: No existe apoyo empírico de que afecte la probabilidad de emplear pasivos financieros, ni se cuenta con antecedentes de estudios de campo que incorporen esta variable. Teniendo en cuenta el argumento de Petersen y Rajan (1994) de que el crédito comercial es el sustituto costoso de los pasivos financieros cuando hay restricciones en el acceso, se esperaría una relación negativa.

- Limitación de la responsabilidad: La evidencia señala que las firmas con formas legales que limitan la responsabilidad tienen mayor probabilidad de emplear pasivos financieros (significatividad al 1\%). En los antecedentes empíricos se encuentra una relación negativa de la tasa de impuestos con el ratio de endeudamiento, resultado contrario al que indica la teoría, ya que mayor tasa implica un mayor escudo fiscal de la deuda. En el presente estudio se mide este efecto indirectamente, a través de la variable responsabilidad limitada. Las empresas con responsabilidad limitada enfrentan en general la máxima alícuota posible en forma fija, mientras que el resto tiene un régimen progresivo, cuyo máximo es también $35 \%$. Entonces se espera que por el lado del efecto fiscal, las empresas con responsabilidad limitada tiendan a emplear más pasivos financieros que el resto, que es precisamente el efecto observado. La limitación de la responsabilidad captaría varios efectos. Primero, la limitación de la responsabilidad patrimonial en sí misma; por un lado se espera que esto disminuya los costos de quiebra del empresario, y por el otro que los entrepreneur con responsabilidad limitada tengan un mayor incentivo para emprender proyectos riesgosos, por lo que enfrentarían mayores restricciones en el acceso al crédito. 
Segundo, como se indicó anteriormente, el efecto del sistema de impuesto a las ganancias. Por último, la obligatoriedad de llevar estados contables para las sociedades con responsabilidad limitada (SA y SRL). Bajo el enfoque de las asimetrías de información, el empleo de un sistema de información ordenado como la contabilidad puede verse como una disminución de la opacidad informativa de la empresa frente a los proveedores de fondos externos. Por este lado el efecto también sería positivo.

- Sector: Se encuentra que las firmas del sector industria tienen más probabilidad de emplear pasivos financieros con respecto a los sectores construcción y agropecuario (significatividad al 5\%). La variable sector se emplea en este trabajo como proxy a la tangibilidad de los activos. En los antecedentes empíricos la tangibilidad de los activos suele medirse a través de la estructura de activos fijos y corrientes, o empleando como proxy el sector al cual pertenece la empresa. Los efectos reportados por los trabajos son contradictorios, como puede observarse en el Cuadro 5. Desde la óptica de la tangibilidad, este estudio encuentra evidencia de un efecto positivo en el empleo de pasivos financieros. Como la categoría base en este caso es la industria, y se espera que empresas de este sector tengan mayor proporción de activos fijos y tangibles que los otros sectores, entonces el efecto de la tangibilidad sería positivo. Sin embargo, estos resultados son considerados con cautela, ya que los sectores construcción y agropecuario tienen baja representación en la muestra: son el $6 \%$ del total.

2. Conclusiones sobre el problema de investigación

Reconsiderando la evidencia hallada sobre las variables explicativas propuestas en las hipótesis de investigación, los 
resultados de las variables de control y la estadística descriptiva, pueden delinearse las siguientes conclusiones sobre el problema de investigación:

¿Qué factores diferencian a las empresas que emplean pasivos financieros (excluido giro en descubierto) de las que no?

Desde el enfoque propuesto como visión gerencial, resulta relevante la actitud frente al endeudamiento personal, reflejada en la experiencia en créditos personales para fines particulares. Esta variable estaría captando por un lado un efecto experiencia y menor aversión por la incertidumbre, y por el otro un efecto oferta de menor opacidad frente a los proveedores de fondos. En ambos casos, se destaca la importancia del entrelazamiento empresa- empresario en las decisiones de financiamiento.

La edad del empresario es otro factor relevante, en línea con lo planteado en el enfoque de ciclo de vida del empresario. Al controlar por los costos personales de quiebra, los objetivos con respecto a la empresa, y el ciclo financiero de la empresa, el estudio estaría captando el efecto aislado del cambio en la aversión al riesgo y a las pérdidas, con la edad.

En cuanto a las variables de los enfoques tradicionales, el tamaño medido como ventas, y la limitación de la responsabilidad en la forma legal surgen como factores significativos, acompañados en menor medida por el sector en el cual opera la firma. Ambas variables podrían estar indicando la presencia de asimetrías de información.

En resumen, tanto el enfoque de visión gerencial como el ciclo de vida del administrador- propietario reciben apoyo 
empírico. En cambio, no se encuentra apoyo para el ciclo de vida de la empresa familiar.

\section{Implicaciones para la teoría}

Brealey y Myers (2006) consideran que "cómo se toman las decisiones en finanzas" es una de las diez preguntas sin resolver en el campo de finanzas corporativas. Buscando responder a cómo se toman las decisiones de financiamiento en las pequeñas empresas, en este trabajo se realiza un replanteo de los enfoques del trade off y la jerarquía financiera desde la óptica de las PyMEs. Con respecto al primer enfoque, se cuestiona la validez descriptiva de una estructura óptima con respecto al valor de la empresa. De hecho, en el relevamiento realizado sólo el 19\% de los encuestados reconoció como su objetivo la maximización del valor de la empresa. Más aún, el 33\% declara como principal objetivo metas personales como dar trabajo a familiares, o asegurar la sucesión de la empresa. Sin embargo, se encuentra que un grupo de empresarios prefiere financiar sus inversiones con una mezcla de capital propio y pasivos financieros, por lo que se podría inferir que reconocen ciertas ventajas y desventajas en el apalancamiento. Al reconocer que no todos los empresarios se comportan maximizando valor, se abre el camino a formular el trade off como complementario a otros enfoques, y no como una explicación universal. Esto constituye un aporte teórico de esta investigación, ya que tradicionalmente se ha trabajado con explicaciones alternativas en vez de complementarias.

El trade off se basa en tres argumentos principales: impuestos, costos de quiebra y asimetrías de información. En el campo de las pequeñas empresas, la dimensión impositiva es especialmente compleja. En el trabajo empírico realizado el efecto 
del impuesto a las ganancias es captado indirectamente a través de la forma legal de limitación de la responsabilidad, por lo que si bien se encuentra que es relevante, es necesario ser cauto con el valor relativo de esta evidencia. La ampliación de los costos de quiebra, incluyendo la dimensión personal como se propone en la visión gerencial, es otro paso más en la adaptación de un enfoque trade off para PyMEs.

En el terreno de la jerarquía financiera, la pregunta radica en cuáles son las razones para preferir al autofinanciamiento al apalancamiento financiero. El deseo de mantener el control y la flexibilidad, y la presencia de costos de transacción son factores que el marco teórico desarrollado propone como relevantes en el contexto PyME. En este trabajo se presenta como explicación complementaria, con apoyo empírico, que las firmas que se comportan de esta forma reflejan un efecto aprendizaje derivado de haber enfrentado mayores asimetrías de información.

El efecto oferta de las asimetrías de información, materializado en racionamiento del crédito y requerimiento de sobre-tasas, ha sido extensamente estudiado a nivel teórico y empírico, tanto en el contexto nacional como internacional, y existe consenso de que afecta en forma significativa a las pequeñas empresas. Este estudio capta también dicho efecto, ya que encontramos que las empresas de menor tamaño tienen menor probabilidad de emplear pasivos financieros. Uno de los aportes del presente trabajo consiste en proponer que el bajo endeudamiento financiero observado en las pequeñas empresas no responde únicamente a este efecto oferta.

Más allá de los dos enfoques tradicionales, las finanzas conductuales son un campo que prácticamente no ha incursionado 
en la problemática de las pequeñas empresas, y que como se muestra en este trabajo, tiene gran potencial de aplicabilidad.

Reconsiderando el trade off, las finanzas conductuales brindan argumentos adicionales. Por el lado de la formación de creencias, si el administrador-propietario actúa con optimismo y sobre-confianza, buscará maximizar el valor fundamental percibido, y minimizar el costo de capital percibido (el cual es inferior al real). En cuanto a las preferencias, la aversión a las pérdidas lleva a una mayor desutilidad frente a los costos de quiebra.

Los modelos de managers optimistas y sobre-confidentes implican también una jerarquía financiera: un administrador de este tipo considerará que la tasa requerida por los acreedores es excesiva en relación al riesgo percibido. Además, la aversión a las pérdidas y a la ambigüedad o incertidumbre (características de las preferencias) también implicarían una preferencia por el autofinanciamiento frente al riesgo del apalancamiento financiero. La evidencia encontrada en esta investigación señala como significativa la experiencia previa con el endeudamiento a nivel personal, resultado que apoya la relevancia de la aversión a la incertidumbre como factor explicativo.

En resumen, esta investigación apoya la postura de que el estudio de las decisiones de financiamiento de las pequeñas empresas requiere de modelos que incorporen facetas características de este tipo de empresa: objetivos mixtos, entrelazamiento empresa-empresario (actitudes, efecto del ciclo de vida) y limitaciones en la administración. Asimismo, las asimetrías de información afectan al financiamiento de las PyMEs, pero no constituyen el único aspecto que las distingue de las grandes firmas. 
Más allá de campo de la estructura de capital y financiamiento, esta conclusión sería potencialmente extensible a la otra gran área de las finanzas de empresa: las decisiones de inversión.

\section{Implicaciones para el diseño de políticas}

Si bien el diseño de políticas de apoyo financiero a las pequeñas empresas es una de las bases que dan relevancia al tema de estudio, el análisis de este tipo de políticas no es parte de los objetivos de esta investigación, sino que forma parte de las líneas de trabajo futuras. Sin embargo, pueden adelantarse algunas consideraciones.

Las políticas de apoyo financiero a pequeñas empresas están construidas sobre esta línea teórica de fallas de mercado. En la Argentina, la Subsecretaría de la Pequeña y Mediana Empresa y Desarrollo Regional (SEPyME) ha desarrollado programas con el objetivo de reducir los costos de financiamiento mediante la bonificación de tasas de interés, y de requerimientos de garantías a las empresas con el sistema de sociedades de garantía recíprocas. Este tipo de políticas solucionaría solo los problemas de financiamiento de empresas que enfrentan racionamiento, o tasas de interés elevadas, o fuertes requerimientos de garantías $^{18}$. Sin embargo, en esta investigación se encuentra evidencia a favor de la existencia de otros factores relacionados con el bajo apalancamiento financiero de las PyMEs, los cuales se derivan de las características propias de este tipo de firmas. Por ejemplo, las

\footnotetext{
${ }^{18}$ La eficacia de estas políticas en lograr dichos objetivos constituye otro tema de estudio.
} 
firmas que nunca emplearían pasivos financieros representan el $14 \%$ de nuestra muestra, y su comportamiento deriva en una ineficiencia económica, porque dejan de realizarse proyectos con VAN positivo.

Entonces, una política que abarque también este tipo de problemas necesitaría tener carácter integral, y no limitarse solo al apoyo financiero: por ejemplo incluyendo capacitación sobre planificación, sistemas de información, manejo de costos, evaluación de proyectos, entre otros.

\section{Limitaciones}

Las limitaciones de esta investigación se centran en dos aspectos: la ausencia de un modelo formal completo y la representatividad de los resultados.

Como puede apreciarse en el desarrollo del trabajo, no existe un modelo formal que integre los distintos aspectos que inciden en la estructura de capital, sino que los distintos enfoques presentan visiones parciales, y a veces no formalizadas.

En cuanto al trabajo empírico, las limitaciones en la representatividad de los resultados surgen por dos frentes. Primero, se propone un enfoque para la pequeña y mediana empresa argentina, pero por motivos metodológicos y presupuestarios, la contrastación se limita a Bahía Blanca. No se puede afirmar que esta muestra, y las conclusiones derivadas de la misma, resulten representativas de la población nacional. Por otra parte, la metodología econométrica elegida se estima mediante máxima verosimilitud, y plantea una limitación en la relación entre el tamaño de la muestra y el número de regresores que se pueden incluir. De todas formas, Agresti (2002) indica que 
probablemente se detecten los efectos más fuertes aún si el tamaño de la muestra no es grande, pero que detectar los efectos más débiles requiere de muestras mayores. Entonces, cabe la posibilidad de que los efectos que resultaron no significativos en esta investigación reporten otro resultado con un tamaño de muestra mayor.

6. Implicaciones para investigaciones posteriores

Las implicaciones para investigaciones posteriores pueden plantearse a nivel teórico y metodológico. En el plano teórico, como se indicó en la sección anterior, existe la necesidad de desarrollar un modelo formal de la demanda, y la interacción con la función oferta, en la determinación de la estructura de capital de las pequeñas empresas.

En el campo metodológico, se abren nuevos caminos en cuanto a la determinación de la población bajo estudio y la especificación de la variable dependiente. El estudio propuesto en esta investigación puede plantearse sobre la población nacional de pequeñas empresas, lo cual permitiría identificar efectos regionales diferenciales. Una segunda definición de la población de interés podría incluir además grandes empresas de capitales nacionales, a fines de estudiar si los efectos personales y conductuales se presentan también en las firmas de mayor tamaño. Por último, la definición más ambiciosa abarcaría un estudio comparado a nivel internacional.

Finalmente, como se señaló anteriormente, el reconocimiento de factores propios de la demanda de financiamiento, que llevan a problemas de sub-inversión, abre un 
campo fértil para el análisis y diseño de políticas integrales de apoyo financiero.

Concluyendo, en esta investigación se propone que en el financiamiento de las PyMEs influyen ciertos factores propios de la demanda, derivados del entrelazamiento empresa- propietario. Los mismos se suman a las variables tradicionalmente estudiadas, que son producto de las asimetrías de información entre firmas y proveedores de fondos. Sobre la base de un estudio de campo realizado en la ciudad de Bahía Blanca, se encuentra evidencia que apoya la relevancia de las variables propuestas. Esto constituye un avance hacia el desarrollo de modelos que caractericen la naturaleza distintiva de las pequeñas firmas.

\section{REFERENCIAS BIBLIOGRAFICAS}

Agrestri, A. (2002), Categorical Data Analysis, Ed. Wiley, $2^{\circ}$ edición. Gainesville, Florida.

Ang, J.S. (1991), "Small Business Uniqueness and the Theory of Financial Management," Journal of Small Business Finance, Vol. 1, pp. 1-13.

Aybar-Arias, C., Casino-Martínez, A. y.López-Gracia, J. (2003), "Capital Structure and Sensitivity in SME Definition: A Panel Data Investigation", http://ssrn.com/abstract=549082. Consultado 05-11-2006.

Baker, M., Ruback, R. y Wurgler, J., (2004), "Behavioral Corporate Finance: A Survey", oct 9, Consultado el 27-052007,en

http://pages.stern.nyu.edu/ jwurgler/papers/bcfsurvey14.pdf Barberis, N. y Thaler, R (2003), "A Survey Of Behavioral Finance", en Handbook of the Economics of Finance, 
Editado por G.M. Constantinides, M. Harris and R. Stulz Elsevier Science B.V, pp. $1052-1121$.

Bebczuk, R (2004), "What Determines the Access to Credit by

SMEs in Argentina?", Documento de trabajo $\mathrm{n}^{\circ} 48$, disponible en:http://www.depeco.econo.unlp.edu.ar

Berger, A N y Udell, G F (1998), "The Economics Of Small

Business Finance: The Roles Of Private Equity And Debt

Markets In The Financial Growth Cycle", Journal of

Banking and Finance, Vol. 22, pp. 613-673.

Brander, J. y Lewis, T.(1986), "Oligopoly and Financial Structure:

The Limited Liability Effect", American Economic Review,

Vol. 76 (5), pp. 956-970.

Brealey, R. A. y Myers, S., C.(2006), Principios de Finanzas Corporativas, Ed. McGraw-Hill, 8 a edición.

Brennan, M y Schwartz, E (1984), "Optimal financial policy and firm valuation”, Journal of Finance, 39, pp. 593-607.

Cardone Riportella, C. y Carzola-Papis, P., (2001), "New

Approaches to the Analysis of the Capital Structure of SME:

Empirical Evidence from Spanish Firms", Working Paper

01-10, Business Economics Series 03, Universidad Carlos III, Madrid.

Cardone Riportella, C. y Casasola Martínez, M., (2003), "What

Do We Know About The Financial Behaviour Of The Spanish SME?: An Empirical Analysis", Working Paper 0337, Business Economics Series 08, Universidad Carlos III, Madrid.

Carland, J. W. III,. Carland, J. W., Carland, J.C y Pearce, J.W. (1995), "Risk Taking Propensity Among Entrepreneurs, Small Business Owners, and Managers", Journal of Business and Entrepreneurship, Vol. 7(1), pp. 15-23.

Chittenden, F, Hall, G. y Hutchinson, P., (1996), "Small Firm Growth, Access to Capital Markets and Financial Structure: 
Review Of Issues and an Empirical Investigation", Small Business Economics, Vol. 8, pp. 59-67.

Dapena y Dapena (2003), "Sistemas De Información en PyMEs y Acceso al Crédito en Contextos de Asimetría de Información", XXXVIII Reunión Anual de la AAEP.

Daskalakis, N, y Psillaki, M. (2005), "The Determinants of Capital Structure of the SMEs: Evidence from the Greek and the French firms",

http://www.univ-orleans.fr/deg/GDRecomofi/Activ

Consultado el 05-06-2006.

DeAngelo, H. y Masulis, R., (1980), "Optimal capital structure under corporate and personal taxation", Journal of Financial Economics, Vol. 8, pp. 3-29.

Diamond, D. (1989), "Reputation Acquisition in Debt Markets", Journal of Political Economy, Vol. 97(4), pp. 828-862.

Fama, E. y Miller, M., (1972), The Theory of Finance. Holt, Rinehart and Wiston, New York.

Fan, J. P.H., Titman, S. y Twite, G. J. (2006), "An International Comparison of Capital Structure and Debt Maturity Choices". AFA 2005 Philadelphia Meetings http://ssrn.com/abstract=423483 . Consultado el 10-11-2006 Filippo, A., Kostzer, D. y Schleser, D. (2004), “ Créditos a PyME en Argentina: racionamiento crediticio en un contexto de oferta ilimitada de dinero", CEPAL - Serie Desarrollo Productivo 154.

Fischer, E., Heinkel, R. y Zechner J., (1989), "Dynamic Capital Structure Choice: Theory and Tests", Journal of Finance, Vol. 44, pp. 19-40.

Gallo, M.A., (1997), La empresa familiar, Biblioteca IESE de Gestión de Empresas, Barcelona.

Gallo, M. A, (1998), La Sucesión en la Empresa Familiar. Servicio de estudios de la Caixa. 
Gallo, M. A., Tàpies, J. y Cappuyns, K., (2004), “Comparison of Family and Nonfamily Business: Financial Logic and Personal Preferences," Family Business Review, Vol. 17 (4), pp. 303-318.

Gellatly, G., Riding, A., y Thornhill, S., (2003), "Growth History, Knowledge Intensity and Capital Structure in Small Firms", Economic analysis (EA) research paper series, MicroEconomic Analysis Division, Statistics Canada.

Gibson, B. (2002), "A Cluster Analysis Approach to Financial Structure in Small Firms in the United States", paper presented at United States Association for Small Business and Entrepreneurship (USASBE) Annual National Conference And Entrepreneurial Bonanza.

Gregory, B T , Rutherford, M. W., Oswald, S. y Gardiner, L., (2005), "An Empirical Investigation of the Growth Cycle Theory of Small Firm Financing", Journal of Small Business Management, Vol. 43 (4), pp. 382-392.

Hall, G., P. Hutchinson, y Michaelas, N., (2006), "East And West: Differences In SME Capital Structure Between Former Soviet-Bloc And Non Soviet-Bloc European Countries", en International Conference on Financing of SMEs in Developed Countries. http://www2.warwick.ac.uk/fac/soc/wbs/conf/int-smefinance/programme/21_-_hall.pdf. Consultado el 7-11-2006. Hamilton, R.T., y Fox, M.A., (1998), "The Financing Preferences of Small Firm Owners", International Journal of Entrepreneurial Behaviour \& Research, Vol. 4 (3), pp. 217238.

Harris, M., y Raviv, A., (1991),"The Theory of Capital Structure”, The Journal of Finance, Vol. 46 (1), pp. 297-355.

Hutchinson, P, Hall, G. y Michaelas, N., (1998), "The Determinants of Capital Structure for Micro, Small and 
Medium Sized Enterprises", International Council for Small Business, Conference Proceedings, Singapore.

Hutchinson, P., (2003), "How Much Does Growth Determine

SMEs' Capital Structure?", presentado en la $16^{\circ}$ Annual

Conference of Small Enterprise Association of Australia and New Zealand.

Jensen, M. y C., Meckling, W. H., (1976), "Theory of the firm:

Managerial behavior, agency costs and ownership structure",

Journal of Financial Economics, Vol. 3, pp. 305-360.

Jensen, M. (1986), "Agency Costs of Free Cash Flow, Corporate

Finance and Takeovers", American Economic Review

Papers and Proceedings, Vol. 76 (2), pp. 323 -329.

Jordan, J., J. Llowe, y Taylor, P., (1998), "Strategy and Financial

Policy in UK Small Firms", Journal of Business Finance \& Accounting, Vol. 25(1) \& (2), pp. 1-27.

Kim, E., (1978), "A mean-variance theory of optimal capital structure and corporate debt capacity", Journal of Finance, Vol. 33 (1), pp. 45-63.

Klapper, L. , Sulla, V. y Sarria-Allende, V. (2002), "Small- and Medium-Size Enterprise Financing in Eastern Europe", World Bank Policy Research Working Paper 2933.

Klapper, L, Sarria-Allende, V. y Zaidi, R., (2006), “A Firm-Level Analysis of Small and Medium Size Enterprise Financing in Poland", World Bank Policy Research Working Paper 3984. Kraus, A. y Litzenberger, R., (1973), "A state - preference model of optimal financial leverage", Journal of Finance, Vol. 28 (4), pp. 911-922.

Leland, H., (1994), "Corporate Debt Value, Bond Covenants, and Optimal Capital Structure," Journal of Finance, Vol. 49, pp. 1213-1252.

Long, J.S (1997), Regression Models for Categorical and Limited Dependent Variables, SAGE Publications. 
Long, JS y Freese, J., (2001), Regression Models for Categorical Dependent Variables Using Stata, Stata Press Publication

Mac an Bhaird, C., y Lucey, B., (2006 ), "Capital Structure and the Financing of SMEs: Empirical Evidence from an Irish Survey", http://ssrn.com/abstract=905845. Consultado el 0511-2006.

Maksimovic, V., y Titman, S., (1991), "Financial Policy and Reputation for Product Quality", Review of Financial Studies, Vol. 4 (1), pp.175-200.

Miller, M. H., (1977), "Debt and Taxes", Journal of Finance, Vol. 32 (2), pp. 261-275.

Modigliani, F. y Miller, M., (1958), "The Cost Of Capital, Corporation Finance and the Theory Of Investment", American Economic Review, Vol. 48 (3), pp. 261-297.

Modigliani, F. y Miller, M., (1963), "Corporate Income Taxes and the Cost of Capital: A Correction.", American Economic Review, Vol. 53 (3), pp. 433-443.

Myers, S. y Majluf, N., (1984), "Corporate Financing and Investment Decisions when Firms have Information that Investors do not have", Journal of Financial Economics, Vol. 13, pp. 187-221.

Myers, S., (1984), "The Capital Structure Puzzle", The Journal of Finance, Vol. 39 (3), pp. 575-592.

Observatorio PyMIs (2004, 2005), Informe a las empresas sobre el resultado de la primera encuesta estructural. Disponible en: www.observatoriopyme.org.ar

Observatorio PyMIs, (2006), Informe sobre inversión y financiamiento de PyMEs industriales. Disponible en: www.observatoriopyme.org.ar

Petersen, M, y Rajan, R., (1994), "The Benefits of Lending Relationships: Evidence from Small Business Data", Journal of Finance, Vol. 49(1), pp. 3-37. 
Rajan, R.G., y Zingales, L., (1995),"What do we Know About Capital Structure? Some Evidence from International Data", Journal of Finance, Vol. 51(5), pp. 1421-1460.

Romano, C., Tanewski, G. y Smyrnios, K., (2000), "Capital Structure Decision Making: A Model For Family Business", Journal of Business Venturing, Vol. 16, pp. 285-310.

Ross, S.A., (1977): "The Determination of Financial Structure. The Incentive Signaling Approach", Bell Journal of Economics, Vol. (8), pp. $23-40$.

Rotstein, F., Briozzo, A. , Esandi, J. y G. Milanesi, (2007). "Análisis Descriptivo de la Estructura de Financiamiento de las PyMEs Bahienses". XXVII Jornadas de la Sociedad Argentina de Docentes de Administración Financiera.

Salloum, D. y Vigier, H., (1997), "Los Problemas de Financiamiento de la Pequeña y Mediana Empresa: la relación Bancos - PyMEs", XXXII Reunión Anual de la $A A E P$.

Salloum, D. y Vigier, H., (1999), "Sobre la Determinación de la Estructura de Capital en la Pequeña y Mediana Empresa", XXXIV Reunión Anual de la AAEP.

Salloum, D, Foco, G y Vigier, H., (2001), "El sistema financiero informal y la asistencia a las PyMes: el caso de Bahía Blanca", Anales de la XXXVI Reunión Anual de la AAEP.

Sarig, O., (1998),"The Effect of Leverage on Bargaining with a Corporation", Financial Review, Vol. 33 (1), pp. 1-16.

Scherr, F., y Hulburt, H., (2001). "The Debt Maturity Structure of Small Firms", Financial Management. http://findarticles.com/p/articles/mi_m4130/is_1_30/ai_7548 1857/ pg_1. Consultado el 07-11- 2006.

Serrasqueiro Da Silva, Z., y Raposo Barata, L., (2003), "Financial Behaviour of Portuguese Firms, an Empirical Approach to SME and Large Firms", XIII Congreso de ACEDE. 
Shefrin, H, M.,(2001), "Behavioral Corporate Finance" , Journal of Applied Corporate Finance, 14(3). Disponible en SSRN: http://ssrn.com/abstract=288257

DOI: $10.2139 /$ ssrn.288257

Sorgob Mira, F., (2005). "How SME Uniqueness Affects Capital Structure: Evidence From A 1994-1998 Spanish Data Panel”, Small Business Economics, Vol. 25, pp. 447-457.

Stiglitz, J. y Weiss, A., (1981), "Credit Rationing in Markets with Imperfect Information"; American Economic Review, Vol. 71 (3), pp. 393 - 409.

Storey,D., (1994), Understanding the Small Business Sector, Ed. Routledge, London.

Titman, S. (1984): "The Effect of Capital Structure on a Firm's Liquidation Decisions", Journal of Financial Economics, Vol. 13, pp. 137-151

Titman S., y R. Wessels, (1988). "The determinants of Capital Structure Choice", Journal of Finance, Vol. 43, pp. 1-19.

Van der Wifst,N. y Thurik, R., (1993). "Determinants of Small Firm Debt Ratios: An Analysis of Retail Panel Data", Small Business Economics, Vol. 5, pp. 55-65. 